\title{
Mesoporous silica nanoparticles for bioadsorption, enzyme immobilisation, and delivery carriers
}

\author{
Amirali Popat, Sandy Budi Hartono, Frances Stahr, Jian Liu, Shi Zhang Qiao* and Gao Qing (Max) Lu* \\ Received 1st March 2011, Accepted 29th March 2011 \\ DOI: 10.1039/c1nr10224a
}

\begin{abstract}
Mesoporous silica nanoparticles (MSNs) provide a non-invasive and biocompatible delivery platform for a broad range of applications in therapeutics, pharmaceuticals and diagnosis. The creation of smart, stimuli-responsive systems that respond to subtle changes in the local cellular environment are likely to yield long term solutions to many of the current drug/gene/DNA/RNA delivery problems. In addition, MSNs have proven to be promising supports for enzyme immobilisation, enabling the enzymes to retain their activity, affording them greater potential for wide applications in biocatalysis and energy. This review provides a comprehensive summary of the advances made in the last decade and a future outlook on possible applications of MSNs as nanocontainers for storage and delivery of biomolecules. We discuss some of the important factors affecting the adsorption and release of biomolecules in MSNs and review of the cytotoxicity aspects of such nanomaterials. The review also highlights some promising work on enzyme immobilisation using mesoporous silica nanoparticles.
\end{abstract}

ARC Centre of Excellence for Functional Nanomaterials, Australian Institute for Bioengineering and Nanotechnology, The University of Queensland, St Lucia, QLD 4072, Australia. E-mail: s.qiao@uq.edu.au; maxlu@uq.edu.au

\section{Introduction}

Over the last decades intensive research and development has focussed on the discovery of new therapeutics. Unfortunately, many new drugs are difficult to administer directly due to their degradability in biological systems. With the use of nanoparticles as carriers, the toxicity and side effects of drugs can be greatly

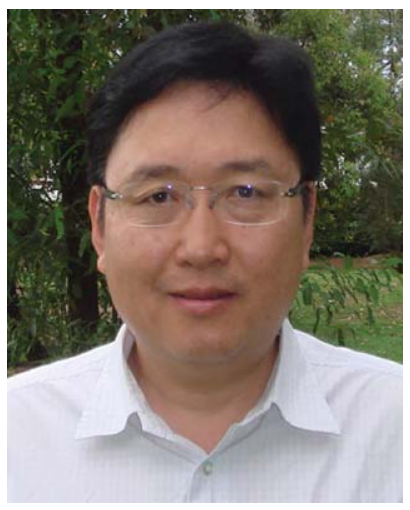

Shi Zhang Qiao
Dr S. Z. Qiao is an Associate Professor at Australian Institute for Bioengineering and Nanotechnology of The University of Queensland. His research expertise is in nanomaterials and nanoporous materials for bioseparation, drug/genelRNA delivery and new energy technologies. He has co-authored more than 100 papers in refereed journals, and he has filed three patents on novel nanomaterials that are promising for bioseparation, drug/gene delivery, fuel cells, photocatalysis and solar cells. In recognition of his research achievements, he was honoured with a prestigious UQ Foundation Research Excellence Award in 2008. He has also been awarded an inaugural UQ MidCareer Research Fellowship, an ARC ARF Fellowship (relinquished) and an ARC APD Fellowship.

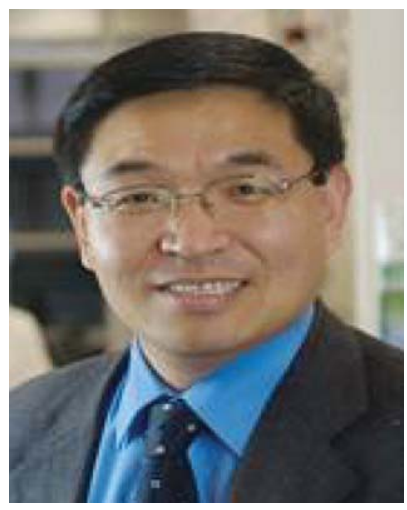

Gao Qing (Max) Lu
Prof. G. Q. Max Lu holds the Chair of Nanotechnology in Chemical Engineering and is currently the Deputy ViceChancellor (Research) at the University of Queensland. His research expertise is in nanoparticles and nanoporous materials for clean energy and environmental technologies. With over 420 journal publications, he is also co-inventor of 18 international patents. Prof. Lu is an Institute for Scientific Information (ISI) Highly Cited Researcher in Materials Science with over 8000 citations. He has received numerous prestigious awards, and he is an elected Fellow of the Australian Academy of Technological Sciences and Engineering (ATSE) and Fellow of The Institution of Chemical Engineers (IChemE). 
reduced and drug molecules can be transfected into different cells via endocytosis. This is in contrast to microparticles, which tend to be taken up only by large cells (e.g., macrophages) or remain outside the target cells. Several different nanomaterials such as layered double hydroxides (LDH), ${ }^{1}$ liposomes $^{2}$ and polymeric nanoparticles ${ }^{3}$ have been considered as delivery vehicles for the controlled and targeted release of biomolecules. Mesoporous silica nanoparticles (MSNs) form another important group of inorganic delivery systems. They are ideal candidates due to their controllable morphologies, mesostructures and porosities, and their high level of biocompatibility and ease of functionalisation.

Since the discovery of the MCM-41s family in 1992, the synthesis of new mesoporous silica materials has advanced rapidly. ${ }^{4}$ The most well known and common families of MSNs include MCM- $n,{ }^{4}$ SBA-n (Santa Barbara amorphous silica), ${ }^{5}$ MSU-n (Michigan State University silica), ${ }^{6}$ KIT-1 (Korean Institute of Technology), ${ }^{7}$ IBN (Institute of Bioengineering and Nanotechnology) ${ }^{8}$ and FDU- $n$ (Fudan University). ${ }^{9}$ Each family has its own unique advantages and disadvantages, and all have been successfully utilised in various applications. These applications include drug delivery, catalyst supports, adsorption and separation of proteins, cell imaging, cell labelling, enzyme adsorption and immobilisation. Additionally, mesoporous silica materials can be synthesised together with other nanomaterials to create new nanocomposites, opening up a wide variety of potential applications. The ready functionalisation of silica materials makes them ideal candidates for bioapplications and catalysis. Furthermore, as porous structures, they exhibit high surface areas, large pore volumes and ordered pore networks. These properties of mesoporous silica allow higher loading of drugs or biomolecules, improved control over the loading and release kinetics, and higher biocompatibility since it is easy for them to be chemically modified.

There have been many excellent reviews regarding synthesis of mesoporous silica and their applications in the past few years. ${ }^{10-17}$ However, with the exponential growth of research in mesoporous silicas over the last five years, it is important to provide a concise and critical review of the latest advances. This review will focus on a few prominent topics such as protein adsorption, drug delivery, DNA/siRNA/vaccine delivery and enzyme immobilisation, including the usage of composite magnetic silica materials as an enzyme nanocarrier. We summarise some of the most significant advances in the field of MSNs for biomedical applications and enzyme immobilisation in Tables 1 and 2, respectively. This review will give an insight into the different types of biomolecules that can be delivered using MSNs and the key factors affecting encapsulation or adsorption of those biomolecules and their release mechanisms. Furthermore, important aspects of cytotoxicity of MSN materials will be discussed.

\section{Mesoporous silica nanoparticles}

\subsection{Introduction to MSNs}

For many biomedical applications, an ideal delivery system should be able to deliver a chemical or biomolecule to a targeted site in a controlled manner. The prerequisites for ideal controlled delivery systems are: (1) biocompatibility and biodegradability,
(2) controlled release of cargo, (3) controlled loading and targeted release of therapeutics, (4) zero premature release and (5) stimuli responsiveness. It is difficult to find an ideal material for a delivery system with all these properties and functionalities. To this end, various delivery systems have been designed and developed. Polymeric nanoparticles, dendrimers, and liposomes were tested as smart materials to achieve an ideal controlled delivery system. ${ }^{18-20}$ Several drug delivery systems have been tested for zero premature release, but in most cases the cargo molecules entrapped in matrices of polymers or inorganic particles would leak out within a few hours due to diffusion or degradation of the polymer matrix. In order to overcome this leaking issue, several nanoparticle-based systems have been recently investigated, including mesoporous silica nanoparticles (MSNs). ${ }^{21}$

Many articles have been published on the synthesis of MCM41 type of materials since Mobil's discovery. However Cai et al. first reported factors affecting morphology control and particle size of MCM-41 type of MSN. ${ }^{22}$ They synthesised nanospheres $(110 \mathrm{~nm})$, sub-micrometre sized rods and micron sized oblates with strong stirring at extremely low surfactant concentration and basic $\mathrm{pH}$ conditions. Furthermore, they proposed a detailed mechanism of the formation of mesoporous silica nanoparticles with different shapes and sizes. They concluded that the synthesis of MCM-41 type of materials involves nucleation and self assembly of silica precursor under alkaline conditions in the presence of a template. The morphology of the particle is then determined by the type of catalyst used, for example, $\mathrm{NH}_{4} \mathrm{OH}$ leads to a rod-like morphology, while $\mathrm{NaOH}$ forms short and smaller size micelles, making the particles spherical.

To date many drugs have been studied for adsorption and release in MSNs (Table 1). However, due to the small pore sizes of the MCM-type materials, the molecule size that could be incorporated and loaded inside the pores was limited to $2-3 \mathrm{~nm}$. Therefore, larger molecules such as proteins, enzymes and DNA could not be used. By changing the $\mathrm{pH}$, temperature, and type of surfactant, a variety of mesoporous materials have been successfully synthesised with varying sizes, shape and morphology. Recently, Nazar and co-workers ${ }^{23}$ reported a strategy for the synthesis of SBA-15 type nanorods with a small particle size (300-600 $\mathrm{nm}$ in length) and large pores $(\sim 6 \mathrm{~nm})$ using a very dilute solution of $\mathrm{P} 123$ in contrast to all other reports based on SBA-15. They showed that due to a low concentration of the template and mild acidic conditions, particles were smaller in size and of different morphology than earlier reported..$^{23} \mathrm{Kim}$ et al. ${ }^{24}$ prepared for the first time SBA-15- type nanospheres with a mean diameter of 500-600 nm using pluronic P104 as a template and tetramethyl orthosilicate (TMOS) as a silica precursor. This is particularly important as SBA-15 type materials exhibit higher thermal and chemical stability than MCM-41 type silicas.

Han et al. synthesised IBN-type mesoporous silica nanoparticles with a 3D cubic ( $\operatorname{Im} 3 \mathrm{~m})$ structure and large pore size by using cationic fluorocarbon surfactants with a higher surface activity and lipophobic nature. ${ }^{23}$ Using different surfactants as templates and trimethylbenzene (TMB) as a pore swelling agent, they synthesised particles with different pore sizes and mesostructures (IBN-1 to IBN-5). They were able to enlarge the pore size to $20 \mathrm{~nm}$. 
Table 1 Different types of drugs loaded onto mesoporous silicas

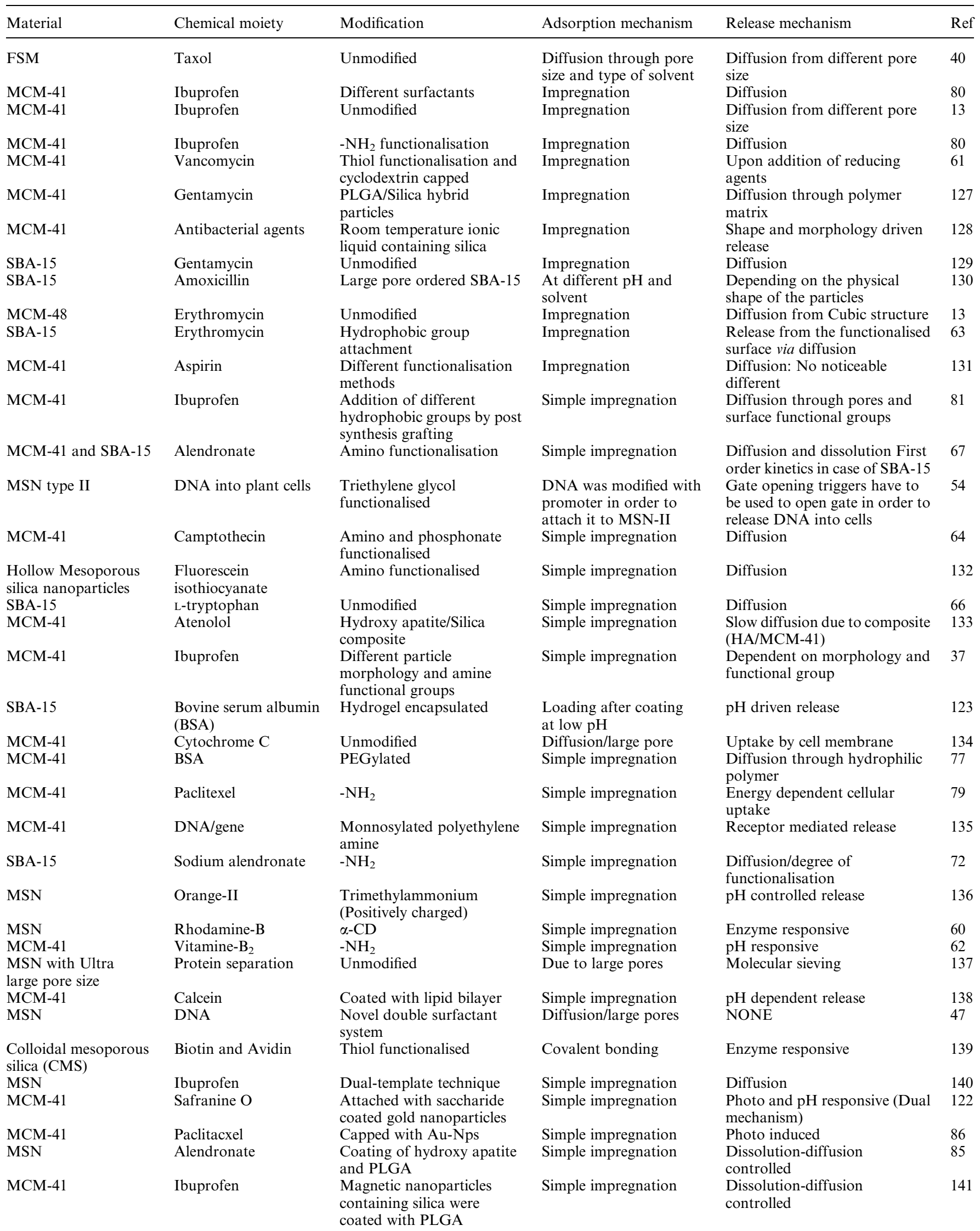


Table 1 (Contd.)

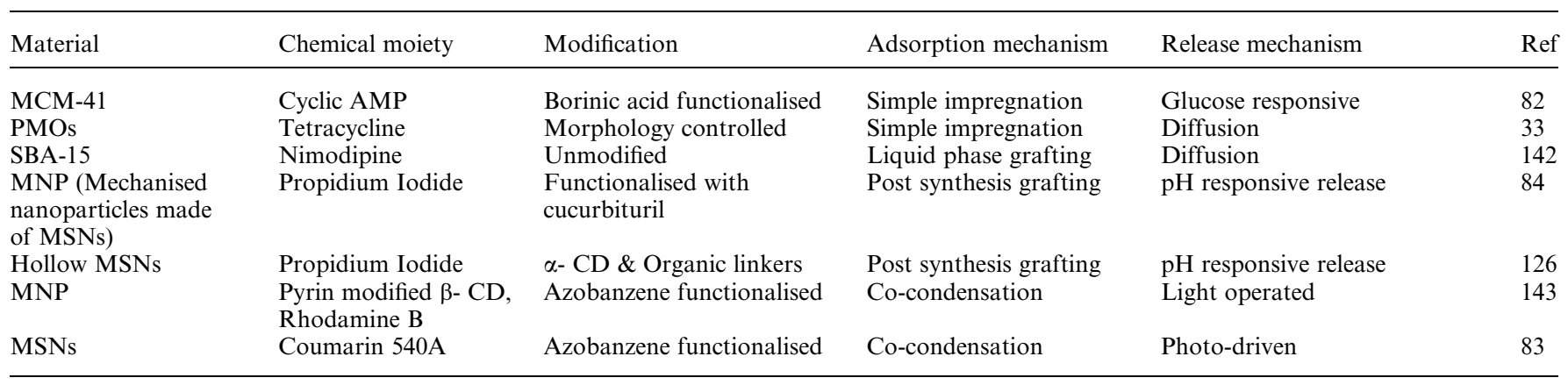

Another very unique 3D cubic structured (Id3d) MCM-48 type of MSNs has been synthesised by many researchers. ${ }^{25-28}$ With the advantage of an open network, it provides easy and direct access to host molecules. However, the synthesis of these types of MSNs requires a time-consuming hydrothermal treatment. Moreover, the large particle size of $>1 \mu \mathrm{m}$ makes them unattractive as drug delivery carriers. ${ }^{25,26}$ Many researchers have tried to decrease the particle size, while keeping monodisperse nanoparticles. Schumacher et al. have developed these types of particles at room temperature with a particle size of $<1 \mu \mathrm{m}$, but still it is not useful for cell-based delivery of proteins and genes..$^{27,28}$

Recently, Kim et al. published a very detailed and sophisticated synthesis process of MCM-48 type spherical monodisperse nanoparticles with a particle size between $50-70 \mathrm{~nm}$, a pore size of 2.3-3.3 nm and very high BET surface area of approximately $1250 \mathrm{~m}^{2} \mathrm{~g}^{-1}$. Synthesis was carried out via the modified Stöber method using pluronic F127 to control particle size and alkyl chain surfactants for pore structure control. They investigated the effect of stirring rate, CTAB concentration, and post thermal treatment onto particle size, pore volume, surface area and pore diameter. So far, this is the only article that reports on monodisperse MCM-48 type of MSNs. ${ }^{30}$ This could be very useful in the field of drug delivery as high surface area, small particle size, and an ordered and unique 3D structure make them ideal for the adsorption of biomolecules. Comparison studies between different types of mesoporous structures with controlled morphology and their effects on adsorption and desorption of biomolecules have not yet been conducted.

Another novel class of MSNs is the hollow mesoporous silica nanosphere. Because of its low density, large surface area and well-defined wall structure, they can be used in a variety of applications including drug delivery. We first synthesised PMO hollow spheres with tunable wall thickness using a novel dual templating approach. ${ }^{31}$ Fluorocarbon and CTAB were used as dual templates and 1,2-bis(trimethoxysilyl)ethane was used as the hybrid silica precursor.

Later, the surface functionalised hollow nanospheres with different terminal groups such as $-\mathrm{SH},-\mathrm{NH}_{2},-\mathrm{CN},-\mathrm{C}=\mathrm{C}$, and benzene were synthesised. Disruptive effects of different functional groups on the structure of the hollow sphere was identified for further functionalisation. ${ }^{32}$ We then used these novel particles for delivery of tetracycline. Adsorption of tetracycline was increased by adding a vinyl group (as opposed to other functional groups such as $-\mathrm{SH},-\mathrm{NH}_{2}$ and $-\mathrm{CN}^{33}$ ) onto the surface of the silica.
Very recently, Liu et al. ${ }^{34}$ reported the synthesis of multishelled hollow nanospheres with an average particle size of $150 \mathrm{~nm}$ (Fig. 1). Multi-shelled spheres can be effectively utilised to adsorb different chemical molecules in each shell. Release of each biomolecule can be tuned using different shell thickness. Moreover, these particles showed very high affinity towards Ibuprofen (448 $\left.\mathrm{mg} \mathrm{g}^{-1}\right)$ due to their low density and high surface area. QDs (Quantum Dots) and Ibuprofen were successfully loaded into shells. Release of Ibuprofen molecules was slow and sustained.

In addition to the above-mentioned MSNs systems, many groups are researching the preparation and characterisation of novel core-shell particles. ${ }^{35,36}$ One such type of systems is yolk shell nanoparticles with a porous shell and a functional core. We synthesised mono-dispersed yolk shell nanoparticles with mesoporous silica nanoparticles as a core and a mesoporous shell with tunable thickness (Fig. 2). ${ }^{34}$ Interestingly, we observed a unique three-step release process of Ibuprofen from the nanoparticles.

\subsection{Physicochemical parameters affecting adsorption and release of biomolecules in MSNs}

Table 1 summarises the drugs, genes, proteins and DNA that have been used, loaded into, or attached to MSN materials. There are four major factors that affect adsorption and release of biomolecules in MSNs.

2.2.1 Particle size and morphology. Monzano et al. studied the effect of particle size on the loading and release of Ibuprofen. They used MCM-41 type particles with a particle size ranging from 490-770nm. They concluded that controlled drug release was achieved with smaller spherical particles. However, in regards to irregular shaped micron-sized particles, drug release was very slow. Additionally, they showed that spherical particles are better candidates for controlled drug release than irregular shaped ones. ${ }^{37} \mathrm{Qu}$ et al. also showed the effect of MSN shape on the adsorption of captopril. They concluded that adsorption of captopril was higher in rod shaped particles than in spherical particles. ${ }^{38}$ Later, Qiao and co-worker ${ }^{39}$ produced helical rod like MSNs with a highly ordered structure. They published detailed mechanisms for the synthesis of these types of 1D rod like particles which showed controlled release of Aspirin.

2.2.2 Pore size. Pore size is one of the most important factors affecting selective adsorption and release of host molecules 
Table 2 Summary of enzyme immobilisation on various mesoporous silica material

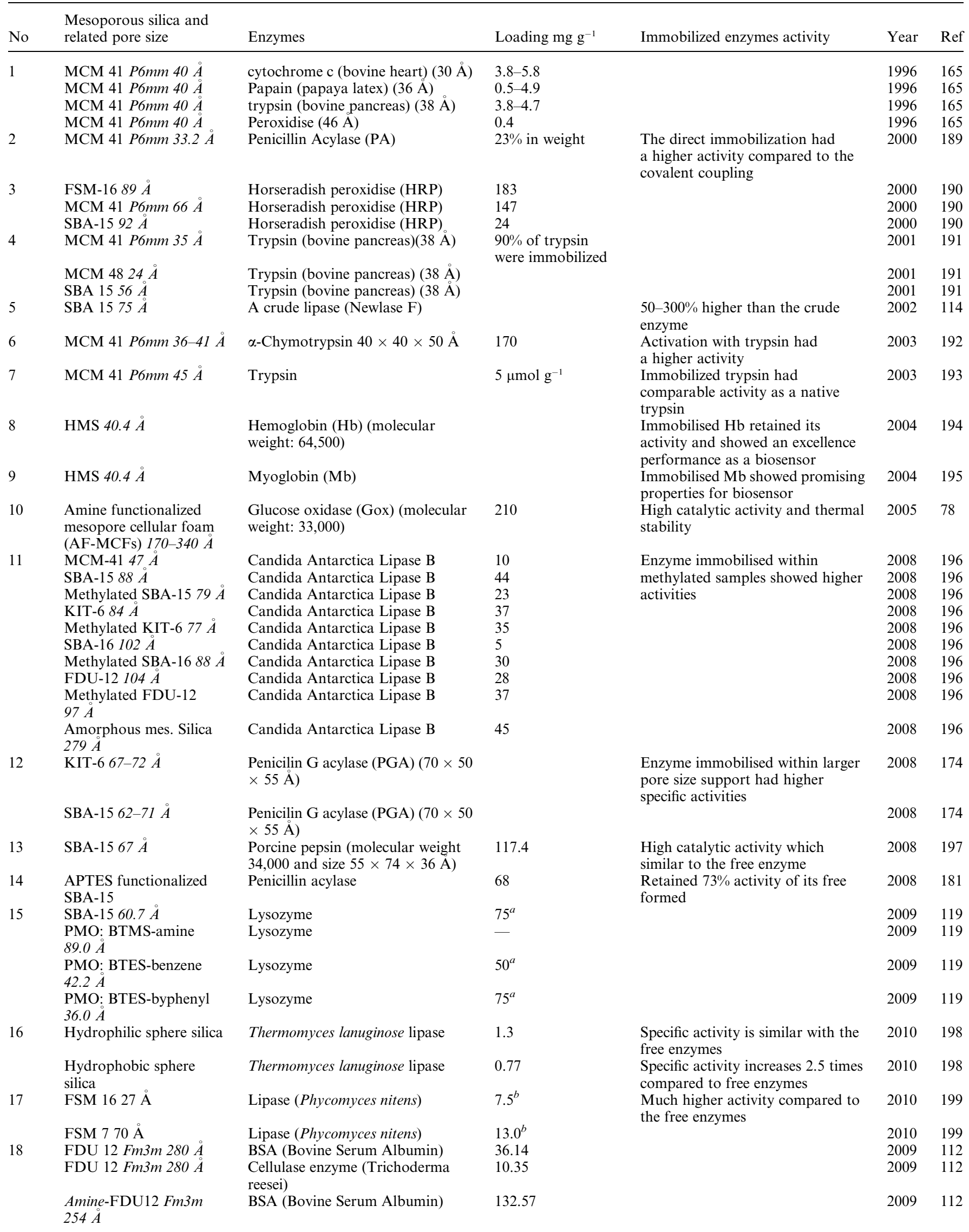


Table 2 (Contd.)

\begin{tabular}{|c|c|c|c|c|c|c|}
\hline No & $\begin{array}{l}\text { Mesoporous silica and } \\
\text { related pore size }\end{array}$ & Enzymes & Loading $\mathrm{mg} \mathrm{g}^{-1}$ & Immobilized enzymes activity & Year & Ref \\
\hline & $\begin{array}{l}\text { Amine-FDU12 Fm3m } \\
254 \AA\end{array}$ & $\begin{array}{l}\text { Cellulase enzyme (Trichoderma } \\
\text { reesei) }\end{array}$ & 21.80 & & 2009 & 112 \\
\hline \multirow[t]{2}{*}{19} & $\begin{array}{l}\text { Functionalized-FDU } 12^{c} \\
\text { Fm } 3 m\end{array}$ & BSA (Bovine Serum Albumin) & $50.9^{d}$ & & 2010 & 182 \\
\hline & $\begin{array}{l}\text { Functionalized-FDU } 12^{c} \\
\text { Fm } 3 m\end{array}$ & $\begin{array}{l}\text { Cellulase enzyme (Trichoderma } \\
\text { reesei) }\end{array}$ & $18.19^{d}$ & $\begin{array}{l}\text { Vinyl-FDU12 showed the highest } \\
\text { activity which retained } 80 \% \text { of the } \\
\text { free enzyme activity }\end{array}$ & 2010 & 182 \\
\hline & APTES-SBA $1599.3 \AA$ & Penicillin $\mathrm{G}$ acylase & $95.9 \%$ & & 2004 & 172 \\
\hline & Glutar-SBA 15 & Penicillin G acylase & $94.1 \%$ & & 2004 & 172 \\
\hline & MPTMS-SBA 1597.1 A & Penicillin $G$ acylase & $85.8 \%$ & & 2004 & 172 \\
\hline & PTMS-SBA $1595.0 \AA$ & Penicillin $G$ acylase & $97.2 \%$ & & 2004 & 172 \\
\hline \multirow[t]{4}{*}{22} & SBA $1566 \AA$ & Porcine Pancreatic Lipase (PPL) & 177 & $36 \%$ & 2010 & 201 \\
\hline & Dimethyl-SBA $1566 \AA$ & Porcine Pancreatic Lipase (PPL) & 178 & $43 \%$ & 2010 & 201 \\
\hline & Diisopropyl-SBA 1566 A & Porcine Pancreatic Lipase (PPL) & 193 & $72 \%$ & 2010 & 201 \\
\hline & Diisobutyl-SBA15 $66 \AA$ & Porcine Pancreatic Lipase (PPL) & 208 & $61 \%$ & 2010 & 201 \\
\hline 23 & $\begin{array}{l}\text { Folded-sheet } \\
\text { mesoporous silica (FSM) } \\
40-85 \AA\end{array}$ & $\begin{array}{l}\text { Alanine racemase from Geobacillus } \\
\text { stearothermophilus }\end{array}$ & $30-60$ & $\begin{array}{l}\text { Retained } 51 \% \text { of the free enzyme } \\
\text { activity. Improved thermal stability }\end{array}$ & 2010 & 202 \\
\hline
\end{tabular}
${ }^{a}$ The adsorption was conducted at $\mathrm{pH}$ of 7.0 and the unit is "amount adsorbed/(mmol $\left.\mathrm{g}^{-1}\right)$ ". ${ }^{b}$ The adsorption unit is "mg/100 mg FSM".
${ }^{c}$ Functionalised FDU-12 includes: amine, vinyl, thiol and phenyl (organosilanes). ${ }^{d}$ The adsorption amount of vinyl-FDU.

including protein, genes, DNA and large antibiotics from MSNs; many studies have highlighted these effects. Hata et al. first reported the effect of pore size and influence of solvent on the loading and release of the anti cancer drug Taxol in 1999. ${ }^{40}$ Further studies by Vallet-Regi and co-workers confirmed the role of pore size as an important factor determining the adsorption and release of biomolecules. There are other pieces of evidence where pore size has effectively altered the loading and release. ${ }^{13,38,41-44}$

Recently, intertest has turned to the synthesis of ordered MSNs with ultra large pores $(10-30 \mathrm{~nm})$. A large pore size is advantageous, especially in cases of protein and DNA adsorption due to their size. Fan et al. were the first to create an ordered mesoporous material with an ultra large pore size of around $30 \mathrm{~nm} .{ }^{45}$ Qiu and co-workers recently synthesised MSNs with ultra large pores (20-40 nm) with interconnected channel structures. These particles have also shown good protein separation capability. ${ }^{46}$ In an another finding, Botella et al. reported monodispersed MSNs with $20 \mathrm{~nm}$ pores using a dual surfactant system and lower synthesis temperature. They observed enhanced adsorption of plasmid DNA due to the large pores, and reported highest DNA content achieved so far on silica based materials $\left(0.07 \mu \mathrm{g} \mathrm{DNA} \mathrm{m}^{-1}\right) .{ }^{47}$

Proteins can interact with mesoporous materials through three main interactions - physical adsorption, encapsulation and chemical binding. Many different proteins have been successfully adsorbed onto the surfaces of mesoprous silica materials. Pore size is also a major factor affecting the loading of proteins into the mesoporous silica network. Small pores result in most of the proteins remaining on the surface and thus not utilising the large internal surface area presented by the pores. It has been shown that large proteins can be easily and quickly adsorbed and released on large pore silica materials such as MCFs. ${ }^{48,49}$

Furthermore, the pore size can provide additional advantages including size selective separation of protein solutions. Katiyar and Pinto were able to demonstrate this with SBA-15 materials using two different proteins lysozyme and bovine serum albumin (BSA). By using confocal scanning laser microscopy, they showed that the smaller protein lysozyme was adsorbed into the pores of SBA-15 and the larger BSA remained outside - not inside - of the pores. ${ }^{50}$ Furthermore, this shows that MSNs can be used for protein separation. Qiao and co-workers combined MCM-41 type MSNs with magnetic $\mathrm{Fe}_{3} \mathrm{O}_{4}$ to produce magnetic silica nanospheres. ${ }^{133}$ Using the resulting magnetic nanocomposite as an adsorbent, they demonstrated the selective separation of cytochrom $\mathrm{C}(\mathrm{Cyt} \mathrm{C})$ from a bicomponent solution of BSA and Cyt $\mathrm{C}$ with a magnetic field. ${ }^{51}$

As discussed previously, limitations in the pore size of silica materials for in vivo delivery is a major hurdle for the loading of large biomolecules, however, there have been some studies showing that RNA and DNA can be successfully incorporated into the silica materials ${ }^{52}$. These RNA/DNA segments or fragments are generally small in size due to the small pore size of the materials. ${ }^{53}$ However, it has been proven to be successful. An excellent example of DNA adsorption and delivery was the work by Torney and co-workers. They demonstrated that by using silica materials as delivery vehicles, with a pore size of $3 \mathrm{~nm}$, the DNA adsorbed MSNs were easily taken up by the plant cell walls and healthy leaves. ${ }^{54}$ Solberg and Landry reported that DNA with 760 and 2000 base pairs in length were adsorbed into various pore sizes of mesoporous silica. ${ }^{55}$ 

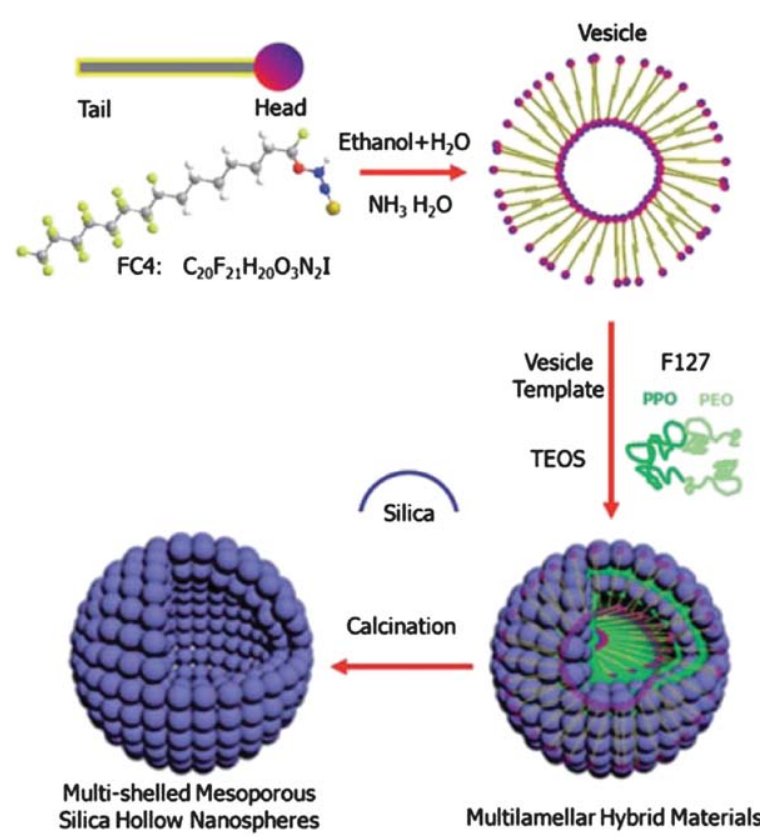

Fig. 1 Schematic illustration of the formation of multi-shelled mesoporous silica hollow nanospheres. ${ }^{34}$

2.2.3 Surface area. Surface area also has a significant impact on the loading and release of cargo molecules in mesoporous materials. It has been well understood that with an increase in surface area, the number of active sites for adsorption increases,
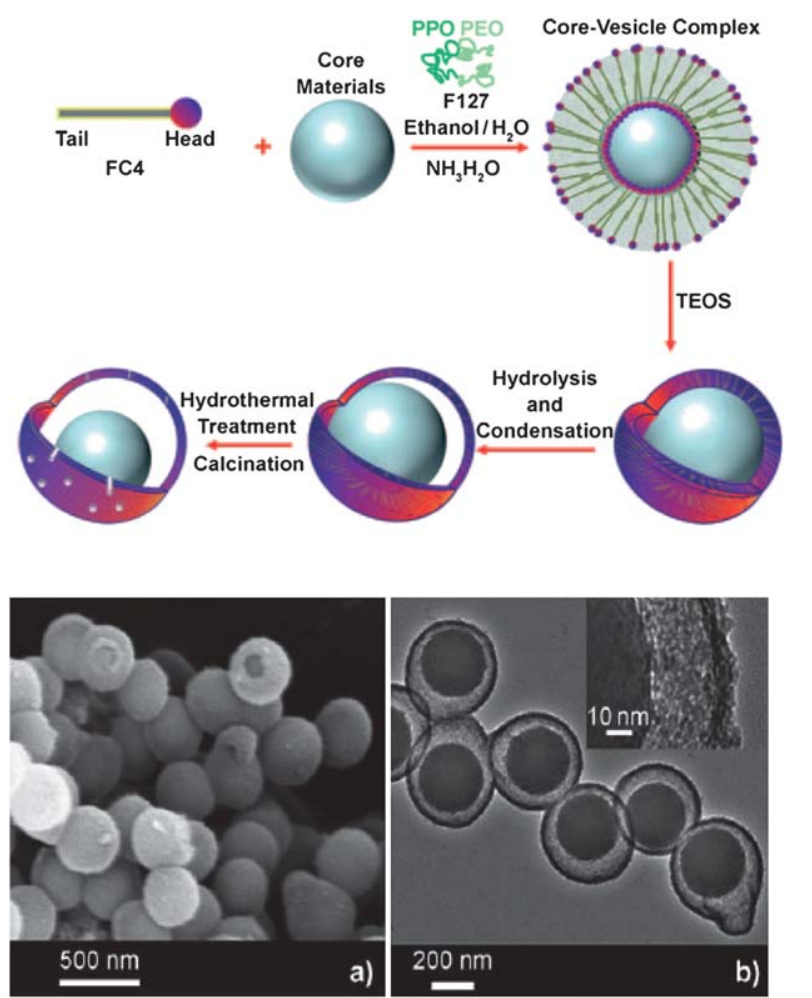

Fig. 2 Procedure for the preparation of yolk-shell structures with a mesoporous shell (top image). Yolk-shell material synthesized using silica spheres with $260 \mathrm{~nm}$ as core. a) SEM image, b) TEM image. ${ }^{29}$ and therefore adsorption of the molecules increases. This has been verified for alendronate for example, under the same conditions. ${ }^{13}$ In an anther study, surface area had only little impact on adsorption of Ibuprofen. ${ }^{56}$ Unfortunately, the volume of literature citing this is not significant.

2.2.4 Surface chemistry and functionalisation of MSNs. Surface functionalisation of MSNs is typically carried out using the one-pot synthesis (co-condensation), post synthesis (grafting), and PMOs (Periodic mesoporous organicsilica) synthesis method. Researchers have observed that the degree of functionalisation is dependent on concentration, molecular size and the hydrophilic/hydrophobic nature of co-condensing agents. Moreover, shape of the particle is also dependent on the type of co-condensing agent used. For instance, a hydrophilic cocondensing agent leads to the formation of small and round particles while hydrophobic one gives rod shape particles. However, one-pot-synthesis suffers from some disadvantages. For example, the degree of structural orderedness decreases with an increase in concentration of the co-condensing agent; a higher concentration can also lead to decrease in pore diameter. ${ }^{57,58}$

An alternative method to attach the desired functional group on to the surface of the silica is the post-synthesis grafting method, whereby organic functionalities are added after removal of surfactant. This method offers the advantage of selectivity, whereby selectively coating of mesoporous silica matrix is more controlled and optimum. However, it can also lead to a nonhomogenous surface coating. This is because the silanol groups on the surface are more accessible than those inside the pore wall.

Surface functionalisation is one of the important factors in controlling the adsorption and release of biomolecules. For instance, surface functionalisation of MSNs with amine groups shows the direct relationship between the release rate and the amount of amino group. Many studies have been carried out to achieve controlled and stimuli-responsive drug delivery systems using functionalised MSNs. ${ }^{37,59-78}$ There are many reasons as to why functionalisation is important, but it is mainly carried out to increase the loading of the molecules and to improve the interparticle and molecular relationships such as increasing the stability of the bond and improving biocompatibility. Other examples include targeted and controlled drug release. For example, the use of amino groups onto the surface of the $\mathrm{MSNs}^{62,67,72,79,80}$ and alkyl chains increases the amount of drug adsorption. ${ }^{63,81}$ This property has been utilised recently to construct stimuli responsive drug delivery systems. ${ }^{61,65,69,75,82-86}$

One of the most promising reports for functionalisation of MSNs is by Mal et al. ${ }^{59}$ where they grafted coumerin onto the outer surface of mesoporous silica using as-synthesised MSNs, so that they could achieve high adsorption selectivity and specificity. Upon UV light irradiation (at $310 \mathrm{~nm}$ ), dimerisation of coumarin closes the gates on the surface of silica. Subsequent irradiation of light at $250 \mathrm{~nm}$ leads to the breakdown of the coumarin dimer, hence releasing the loaded compound loaded inside the pores. ${ }^{59}$

Many studies have shown that surface functionalisation improves the adsorption capacity of the proteins by introducing electrostatic bonding. Uses of amine groups, disulfide bonds or with the introduction of thiols have significantly improved adsorption capacity of many drugs (Table 1). Amino silicas are 
one of the most widely used functional groups with regards to protein binding and immobilisation. Many researchers have shown that the amino functionalisation can give the material an overall net positive charge, thus improving electrostatic bonding with biomolecules. The functionalised materials then display greatly enhanced bio-adsorption capacity compared to the unfunctionalised or native counterparts. ${ }^{68,73,78,87}$

\subsection{Other factors affecting the adsorption and release of biomolecules in MSNs}

One of the important factors influencing the amount of protein adsorbed onto the surface of mesoporous silicas is the $\mathrm{pH}$ at which the adsorption is carried out. Various studies using silica materials as adsorbents have shown that the maximum adsorption of protein occurs at or near the isoelectric (pI) point of the protein. For example, myoglobin, cytochrome c (cyt c) and (BSA) have been shown to have a higher adsorption capacity onto the materials at a $\mathrm{pH}$ equal or less than the $\mathrm{pI}$ point of the protein. ${ }^{8-91}$ This is caused by the electrostatic interactions between the protein and the MSNs. Because the repulsive forces between the adsorbed protein on the surface of the material and protein left in solution are minimal at its pI point. ${ }^{91}$

MSNs have been used to attach many polymeric structures to achieve controlled and predicted release of cargo molecules. ${ }^{47,92}$ Rosenholme et al. recently coated mesoporous silica with polyethylineimine (PEI) and it was further modified using a fluorescent component to track MSNs in cells. They showed that functionalised MSNs were five times more internalised into HeLa cells than to unfunctionalised particles. PEI functionalised particles were stable, nontoxic, and further used to attach other biomolecules such as folic acid and fluorescent dyes effectively. ${ }^{93}$

The literature cited above shows the versatility and effectiveness of MSNs not only as a carrier for adsorption and release of host molecules but also as a suitable means for achieving effective surface chemistry. In contrast to this, a study on structural activity relationship for MSN in drug delivery showed that surface functionalisation did not always have an impact on adsorption and release. ${ }^{94}$ They found the least influence of the surface amino group on adsorption and release of salicylic acid from the MSN support. Hence, it is necessary to take into account other factors such as pore size, pore volume, surface area and shape of MSN for the optimisation process. The above studies on the factors affecting adsorption and release suggest that pore size, surface area, shape and surface area, and surface functionalisation all contribute to the adsorption in, and release from, MSNs.

By creating a coating on the silica, it is also possible to increase the loading of DNA on the surface of MSNs, while having a drug loaded inside of the pores. This can effectively increase the biocompatibility of the material and can improve the uptake into cells. For example, coating various molecular weights of PEI on the surface of mesoporous materials can increase their adsorbed amount of DNA and siRNA. This coating can then improve the delivery of the drug Paclitaxel as the positive charge of the polymer coating allows the particle to easily transfect inside the cell. ${ }^{76}$ This PEI coating has also been shown to be effective in the delivery of the siRNA into mammalian cells.
The particles were taken up into the lysosome of the cells where siRNA was released. Plasmid DNA was also loaded on the PEI coated MSNs and effectively delivered into cells. ${ }^{96}$ Mesoporous silica nanoparticles have been used as dual drug delivery carriers, where drug molecules can be adsorbed in mesopores and SiRNA conjugated on the surface. It showed improved uptake and reduced cytotoxicity (Fig. 3). ${ }^{95}$

As many new vaccines use only fragments of the virus compared to the whole antigen, mesoporous silica can be useful in the protection and delivery of antigens to targeted cells. There have been a few studies showing that the mesoporous silica acts as good adjuvants, resulting in an increase in the efficacy of the vaccine. Mercuri and co-workers demonstrated that SBA-15 loaded with a $16.5 \mathrm{kDa}$ recombinant protein Int $1 \beta$ from E.coli can protect mice from the venom of snake species Micrurus. Compared with conventional adjuvants, it was shown that the antibody response was much higher than what was currently available. ${ }^{97}$ Composite materials such a poly(d,1-lactide-co-glycolide) (PLGA) coated MCM-41 was also shown to be effective in the use of prime boost vaccinations. ${ }^{98}$

\section{Cytotoxicity of MSNs}

Due to the varied structure of mesoporous materials and the different synthesis methods, examining biocompatibility is a challenge as it is often difficult to create similar physiological conditions both in vitro and in vivo. ${ }^{37}$ At relatively low doses, silica nanoparticles are non-toxic but become toxic at higher doses as they induce cell damage. ${ }^{99}$ Early cytotoxicity tests showed that compared to solid silica spheres, MCM-41 was found to be less toxic. ${ }^{100}$ Recently, many studies have focussed on the cytotoxicity of mesoporous silicas, many of which concluded that the type of surface functionalisation can have a drastic effect on the toxicity of the material. ${ }^{\mathbf{1 0 1 , 1 0 2}}$ In vitro studies have shown extensively how mesoporous silica interacts with various cell lines. Some of these include 3T3 endothelial cells, ${ }^{103}$ human colon carcinoma (Caco-2), ${ }^{104}$ glioma cells ${ }^{101}$ human mesenchymal stem cells $^{105}$ and HeLa cells. ${ }^{106-108}$

Several articles reported the influence of size dependent cytotoxicity. In human monocyte-derived dendritic cells, there exists a size effect where larger micron sized silica particles $(2.5 \mu \mathrm{m})$ are more toxic than smaller sub micron $(270 \mathrm{~nm})$ sized mesoporous silica with higher dosages being more toxic than lower dosages. ${ }^{109}$ This size effect can also be observed where human endothelial cells are used with amorphous silica particles. Silica below $20 \mathrm{~nm}$ was much more toxic than silica particles that were 104 and 335 $\mathrm{nm}$ in size. These larger particles showed very little toxic effects. ${ }^{110}$ Having particles in the sub-micron range below $500 \mathrm{~nm}$ is desirable as they are easily taken up by the cell through endocytosis and can be seen localised in the lysosomes of the cell. ${ }^{111}$

Dosage is also an important factor, which needs to be determined. Researchers have shown that there is a dosage effect as MSNs are relatively non-toxic in low concentrations. In a study on COS-7 and MDA-MB-468 cells, it was found that at low concentrations below $25 \mu \mathrm{g} \mathrm{mL} \mathrm{mL}^{-1}$, there was very little toxicity. Above this level, the particles started showing some toxic effects. $^{112}$ 


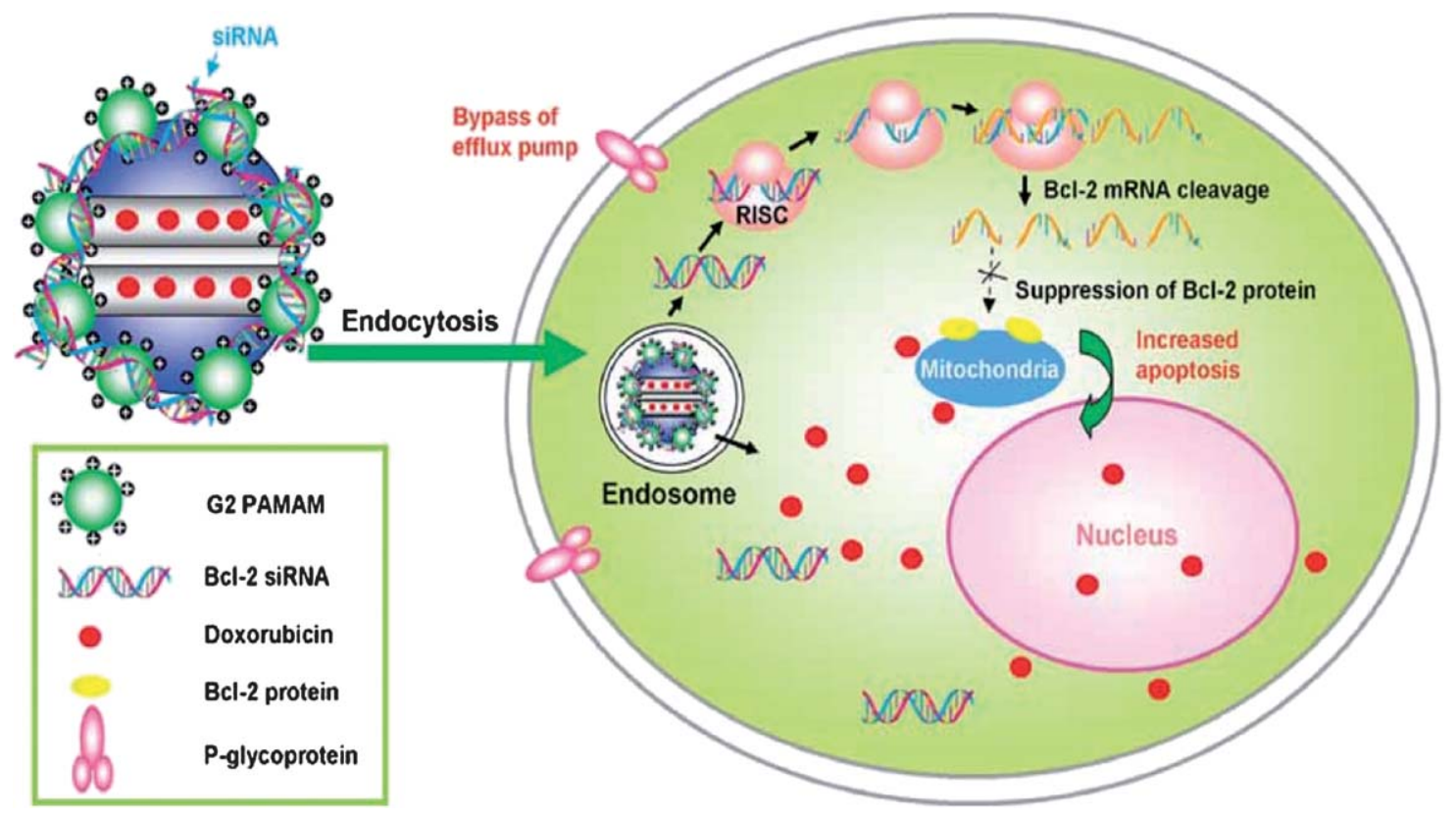

Fig. 3 Schematic and uptake mechanism of drug loaded and siRNA coated mesoporous silica. ${ }^{95}$

The synthesis method used can also play some part in the toxicity as demonstrated by He and co-workers when they tested different MCM-41 type particles synthesised using CTAB, Triton and SDBS on MCF-7 cells. They found that the order of toxicity was CTAB > SDBS > Triton. However, CTAB MSNs performed the best when it came to efficacy. ${ }^{113}$ Furthermore, the effect of the shape of the particle appears to have little effect on the toxicity in A375 melanoma cells using spherical MSNs (100 nm diameter), short rods (240 nm length) and long rods (480 nm length). ${ }^{114}$

The effect of mesoporous silica materials on hemolytic activity is important in order to understand how the materials will interact with blood. In a study by Lin and Haynes, they found that there were significant effects of size, porosity and dosage on the activity of the hemolytic cells. They reported that MSNs with ordered structures reduce the activity of these cells compared with the solid nonporous particles of similar size due to a reduction in the amount of silianol groups on the surface. However, this could be overcome with the addition of polyethylene glycol (PEG) coatings, which were also able to increase the activity. ${ }^{115}$ Hemolytic assays have recently been tested with hollow mesoporous silica. Again, at low dosages (up to $1600 \mu \mathrm{g}$ $\mathrm{ml}^{-1}$ ) these hollow mesoporous silica showed no effect on the activity of the cells. ${ }^{116} \mathrm{He}$ et al. obtained similar results that PEGylated MSNs greatly influenced the non specific serum binding and had showed significantly reduced haemolysis rate compared to non PEGylated MSNs. ${ }^{117}$

In vivo testing of the MSN particles has been so far limited to small rodents such as mice and rats. Hudson and co-workers tested the biocompatibility of three main types of silica nanoparticles MCM-41, SBA-15 and MCF. They used several different sites of injection such as intravenous, intraperitoneal and subcutaneous. The systemic biocompatibility of such nanoparticles was questioned as mice injected intravenously had rapid deaths and some deaths were also caused from the intrperotoneal injection. Subcutaneous injections were relatively safe as none of the animals died. ${ }^{118}$ However, the dose rates were quite high being $0.17 \mathrm{~g} \mathrm{~kg}^{-1}$ for rats and $1.2 \mathrm{~g} \mathrm{~kg}^{-1}$ for mice and the MSN nanoparticles were not functionalised. At a dosage of MSNs at $40 \mathrm{mg} \mathrm{kg}^{-1}$ into the tail base, PEI coated MSNs had no apparent toxic effects on the mice. This difference between the in vivo and in vitro tests is due to different types of cells which are present in the body. Instead of testing on one type of cell, the body has several defence mechanisms, which are able to combat the entry of foreign objects. ${ }^{76}$ The biodegradability of silica particles has been shown in mice with the use of fluorescent labelled silica particles. Again the dose rate was kept low at $20 \mathrm{mg} \mathrm{kg}^{-1}$ and the particles were cleared from the body through the renal system. ${ }^{119}$

Although there have been several studies on in vivo behaviour of MSNs, none of the studies has explained the distribution and elimination of MSNs in different organs. Recently, Souris et al. showed hepatobiliary excretion of MSNs. ${ }^{120}$ They used positively charged MSNs with different charge densities for their studies. Using in vivo and ex vivo fluorescence imaging and inductively coupled plasma-mass spectroscopy, they explained the elimination behaviour of MSNs from liver. They prepared two different types of positively charged MSNs, MSN-NH2-ICG(Indocyanine green) with zeta potential of $+34.4 \mathrm{mV}$ at physiological $\mathrm{pH} 7.4$ and MSN-TA-ICG with a zeta potential of $-17.6 \mathrm{mV}$. Their results showed that MSN-NH2-ICG underwent rapid uptake and elimination via liver while MSN-TA-ICG possessed high uptake and retention in liver. It is interesting to note that charge type and density can be used as a technique to control the residence time of nanoparticles inside the body. ${ }^{\mathbf{1 2 0}}$

\section{Stimuli responsive MSNs for adsorption, controlled and targeted delivery}

Traditional delivery systems based on polymers and other types of inorganic materials do not exhibit stimuli responsiveness. 
Especially with polymeric systems, there is always a danger of premature release of cargo molecules before reaching the site of action. Many stimuli responsive systems attempted to overcome the disadvantages of established systems using MSNs as carriers for targeting cells. These systems are mainly activated by chemical triggers such as $\mathrm{pH}$, enzyme, functional groups, temperature or photons to achieve the desired controlled and predictable release of biomolecules (Table 1) at the desired site.

\section{1. $\mathrm{pH}$ responsive system}

$\mathrm{pH}$ is one of the most widely used biological commands to trigger drug release since the $\mathrm{pH}$ within the body and biological cells has been well known and it is easy to target a particular organ on the basis of $\mathrm{pH}$. In the last few years, many $\mathrm{pH}$ responsive systems based on MSNs have been developed to release various types of molecules like drugs, dyes and other chemical moieties. ${ }^{\mathbf{8 4 , 1 2 1 - 1 2 5}}$

Cyclodextrin and PEI complexes were utilised by Kim and coworkers to achieve release in an acidic environment. Guest molecules were first loaded into pores and then Cyclodextrin (CD)/PEI inclusion complexes were attached onto the surface of MSNs. Due to the bulkiness of these compounds the cargo is protected until polypseudorotaxane is ruptured. Under acidic conditions, the CD complex can be broken and hence release of cargo. ${ }^{74}$ Zink and co-workers recently reported a promising $\mathrm{pH}$ operated, mechanised, nanoparticles-based system with precise control over the release into the lysozyme and cells where the environment was acidic. They modified amino-functionalised MSNs with a pumpkin-shaped cucurbituril forming a $\mathrm{pH}$ dependent complex with the silica. At lower $\mathrm{pH}$ levels, clock like mechanised particles opened up and released propidium iodide (PI); the clock closed at higher $\mathrm{pH}$ levels. ${ }^{84}$

In another example, Zink and co-workers showed that a similar type of release action could be achieved using cyclodextrin derivatives as $\mathrm{pH}$ responsive linkers (Fig. 4). ${ }^{126} \mathrm{pH}$ based delivery of Vitamin B2 was also achieved using amino functionalised nanoscopic gates ${ }^{62}$ Much effort is devoted to $\mathrm{pH}$ based systems that releases cargo in an acidic environment due to its applicability into lysozymes and cancerous cells where $\mathrm{pH}$ is mildly acidic. However, these systems can also be utilised for conventional drug delivery where neutral $\mathrm{pH}$ is equally important to deliver drugs into the intestine. There are very few examples showing release at neutral $\mathrm{pH}$. Kawi and co-workers made polyacrylic acid coated MSNs to achieve the release of protein at physiological $\mathrm{pH} .{ }^{123}$ Hence, research based on MSN lacks conventional targets such as the colon, small intestine, and liver. It will be interesting to see the effect of these novel nanoparticles upon these human organs.

\subsection{Enzyme responsive systems}

Zink and co-workers developed a dual snap-top system specific to liver esterases, which released the cargo upon addition of the enzyme (Fig. 5). Other examples such as bitin-avidin capped MSNs as a protease responsive and lactose coated MSNs based enzyme responsive system make these systems versatile as it can be utilised for many enzymes. ${ }^{60,122,139}$ In addtion to this, Park et al. prepared alpha-amylase and lipase responsive MSNs using $\beta$-CD capping. ${ }^{144}$
Very recently, Chen et al. ${ }^{145}$ prepared temperature and enzyme responsive MSN based scaffolds. These nanovalves can respond to both external stimuli, temperature and internal stimuli such as deoxyribonuclease I, an enzyme making them ideal for cellular delivery. Anticancer drugs such as camptothecin and floxuridine were successfully loaded and released with the above-mentioned triggers. Above examples showed the capability of these systems for drug and gene delivery. To date there are only a few examples of enzyme-responsive systems based on MSNs. Moreover, there are no reports of performance of these systems in vivo or ex-vivo.

\subsection{Chemical trigger responsive systems}

Lin and co-workers reported many systems with zero premature release of biomolecules based on the MCM-41 type of MSNs. ${ }^{54,61,82,86,128,134,146,147}$ A classical example of their work was MSNs capped with CdS nanoparticles to achieve release upon amidation. They showed that coated CdS nanoparticles acted as a gate-keeper for the release of biomolecules. An antibiotic Vancomycin was successfully loaded and released depending on the degree of cleavage of the disulfide bond. ${ }^{61}$ Recently, they reported a magnetic nanoparticles coated MSNs (nanorods) system with zero premature release (Fig. 6). Instead of CdS nanoparticles they used supraparamagnetic iron oxide nanoparticle as a coating material showing that release was induced by anti-oxidants. ${ }^{147}$

A recent example of a stimuli responsive mesoporous silicabased delivery system is the glucose responsive delivery of insulin. As shown in Fig. 7, gluconic acid modified insulin proteins (G-ins) were immobilised onto the exterior surface of aminopropyl functionalised mesoporous silica.

Saccharides, for example glucose, can trigger the release of protein, which can then release the cyclic adenosine mono phosphate (AMP) in cells. cAMP then activates the $\mathrm{Ca}^{2+}$ channels in beta cells of the pancreas and hence releases insulin. Results demonstrated good in vitro and ex vivo insulin release. ${ }^{82}$ This system can potentially be used for diabetic patients who are suffering from cellular problems related to insulin release.

\subsection{Thermal responsive systems}

Temperature sensitive polymers are used in many drug delivery systems due to their unique properties such as their ability to swell above certain temperatures and shrink below certain temperatures. Such systems can be useful in biological systems to achieve stimuli responsiveness if necessary. Poly- $N$-isoproplyacrylamide (PNIPAm) (which can be used for delivery of biomolecules) is well known for its temperature responsive properties and was coated on double bond functionalised silica microspheres by radical co-polymerisation. ${ }^{148}$ Recently, Chung et al. prepared similar composite particles using aromatic functional groups grafted onto the surface of MSN followed by RAFT (Reverse Addition - Fragmentation Chain Transfer Reaction). More importantly they found that the temperature responsive conformation changes in PNIAm can bring about changes to the silica structure. This strategy can be utilised to prepare stimuli responsive MSN based nanovalves, where drugs can be loaded inside the porous structure and released at a certain temperature. ${ }^{149}$ Using the novel W/O pickering 

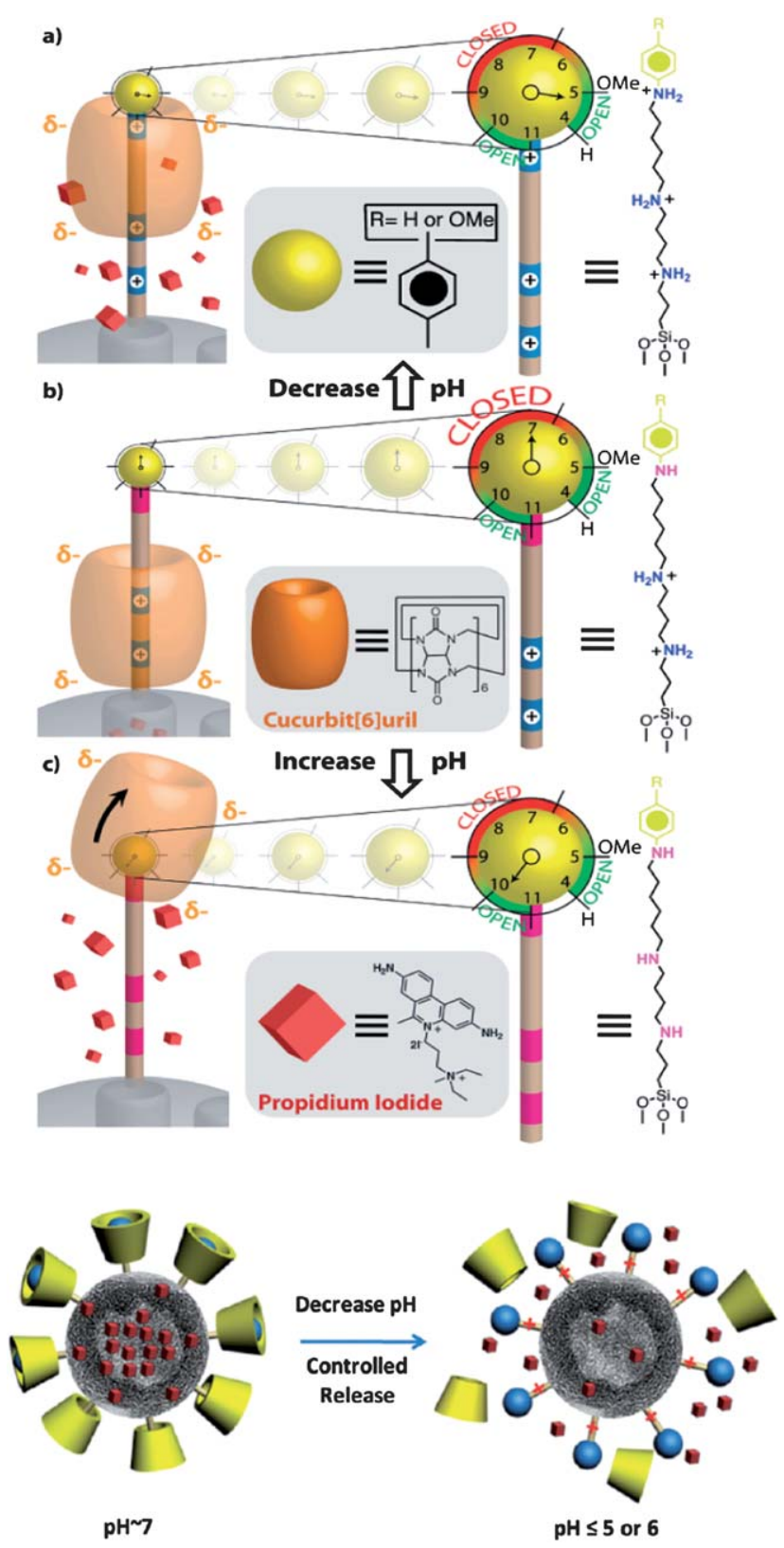

Fig. 4 Design of $\mathrm{pH}$ dependent systems based on MSNs by changing the value of $\mathrm{R} ; \mathrm{pH}$ response can be fine tuned and release of propidium iodide can be controlled ${ }^{84,126}$

emulsion based technique and solid silica sphere as a stabiliser, Zhang et al. prepared temperature responsive hybrid capsules made up of PNIPAm and polymethyl methacrylates (PMMA). Ibuprofen release from the composite particles was controlled by temperature and wall thickness of the polymer. ${ }^{150}$ An interesting system is recently designed to contain zinc-doped iron oxide nanoparticles within mesoporous silica network and pesudotaxanes. Upon AC magnetic field local internal heat (thermal energy) opens the molecular gates to deliver drugs. ${ }^{151}$

\subsection{Polymer coated MSNs}

Recently, many studies have examined the coating of MSNs with a polymer because of its broad applicability in drug delivery,

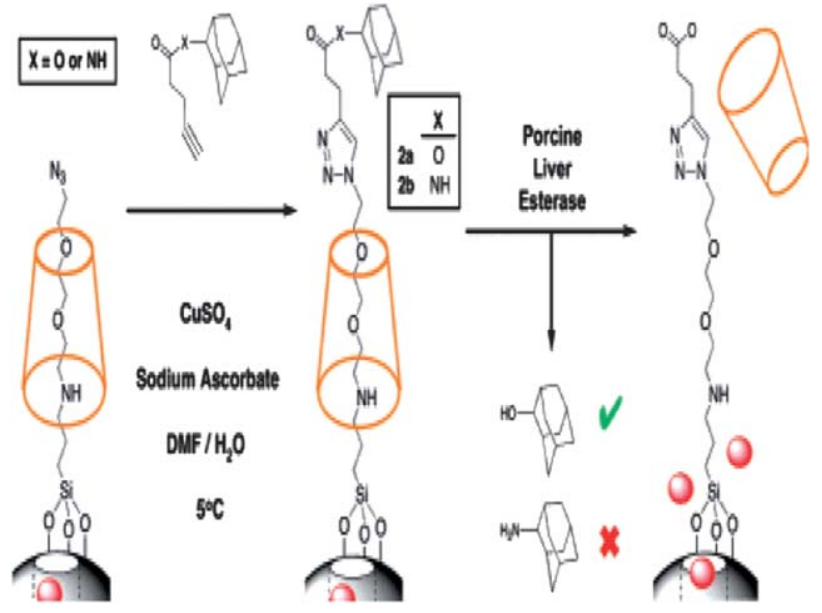

Fig. 5 Enzyme responsive snap-top system based on MSNs. ${ }^{60}$

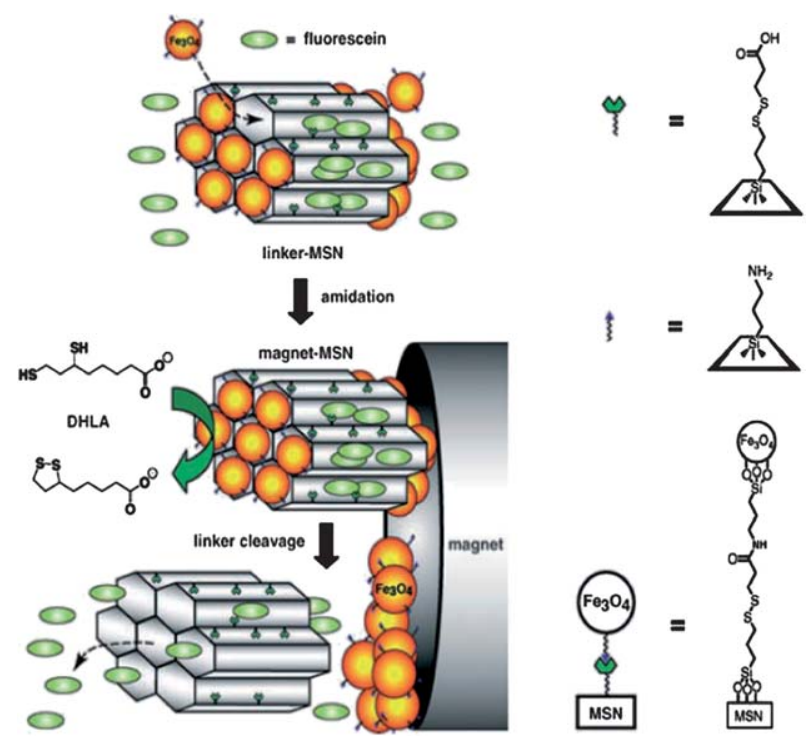

Fig. 6 Schematic of the stimuli-responsive delivery system (magnetMSNs) based on mesoporous silica nanorods capped with superparamagnetic iron oxide nanoparticle. ${ }^{147}$

gene delivery and other biomedical applications. Coating of silica based inorganic nanoparticles with biodegradable polymers such as polymethyl methacrylates (PMM), polystyrene and polylactic acid (PLA) have been extensively studied. ${ }^{47,92,152}$ Such a coating offers many advantages over uncoated nanoparticles like controlled and sustained release, stimuli responsiveness towards $\mathrm{pH}$, enzyme and photon or light. ${ }^{124,152,153}$

Many methods have been developed in the past to coat a polymer onto a mesoporous support including free radical polymerisation, reversible addition-fragmentation chain transfer (RAFT), emulsion polymerisation, and solid-oil-in water emulsification $(\mathrm{S} / \mathrm{O} / \mathrm{W}) .^{92,124,127,152,153}$

Shi et al. developed hydroxyapatite (HA) polylactic-co-glycolic acid (PLGA) coated composite microparticles for controlled release of biophosphonate additives based on a S/O/W method. They showed that coating mesoporous silica with barrier layers such as a polymer can effectively reduce the burst 


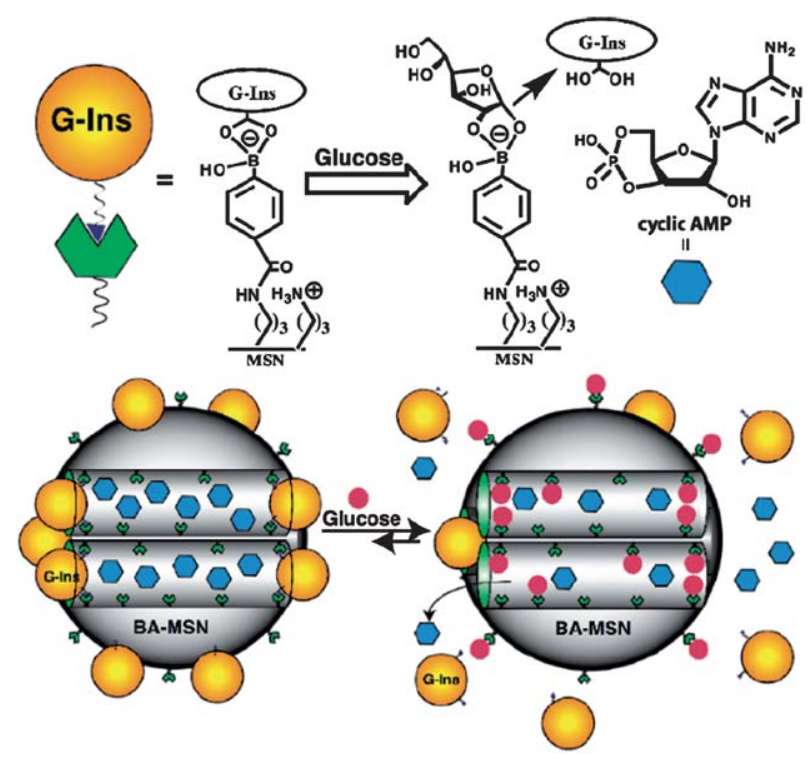

Fig. 7 Glucose responsive MSN based delivery of Insulin. ${ }^{82}$

release of a drug or biomolecules from uncoated nanoparticles (Fig. 8). Interestingly, coated particles were less cytotoxic than uncoated particles and showed sustained release of aldreonate over one month. ${ }^{85}$ It was an interesting approach to coat a layer of HA first onto mesoporous silica to protect biomolecules and then coat PLGA using the $\mathrm{S} \mathrm{W}^{-1} / \mathrm{O}$ emulsification method as it showed a decrease in the burst release. ${ }^{85}$

Huang et al. carried out a similar study where they used the same method $(\mathrm{S} / \mathrm{O} / \mathrm{W})$ to coat PLGA onto magnetic mesoporous silica spheres. The composite particles were several microns in size and showed an effective decrease in burst release of Ibuprofen under simulated conditions. ${ }^{141}$ One of the disadvantages of this method is that the effect of various formulation variables on the size, shape and release of drugs is poorly understood. Particle sizes of composite microparticles are around $100 \mu \mathrm{m}$, which makes this system less useful for cellular delivery and specific drug target delivery. To overcome this problem, Gao et al. reported a novel method to effectively coat several layers of a polymer to get a $\mathrm{pH}$ responsive release of Ibuprofen. Poly-methylacrylic acid-co-vinyl triethoxylsilane (PMV) was successfully coated onto mesoporous silica by the free radical polymerisation method (Fig. 9). Their results suggested that the polymer was coated onto mesoporous silica without altering the particle size too much. These composite nanoparticles showed the $\mathrm{pH}$ responsive release of Ibuprofen. ${ }^{124}$ Recently, Ho et al. prepared PLGA coated composite microparticles using a novel dual concentric ultra sonic atomisation method for DNA prime boost vaccination. The main advantage of this method is that it produces smaller size particles. Results showed that using this novel technique, particles of up to $6 \mu \mathrm{m}$ can be formed. This cannot be utilised for cellular drug delivery due to its size. However, this is the first report of small composite MSN-PLGA microparticles. Moreover, they showed a remarkable loading efficiency of up to $98 \%$. Particles were uniform in particle size and morphology and showed almost zero release for long periods of time. However, this technique is not reproducible and it is hard to control certain factors such as particle size and wall thickness during scale up. ${ }^{154}$
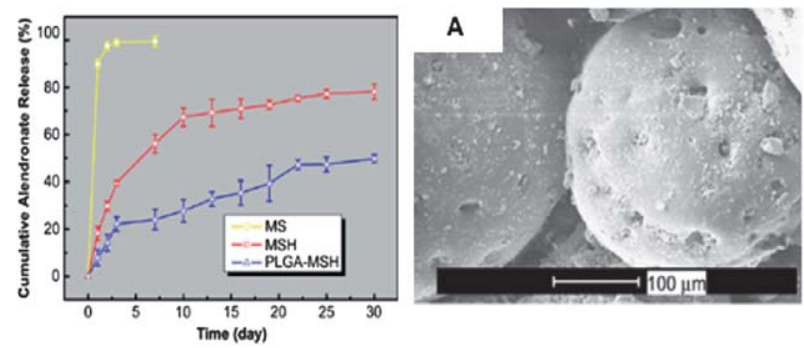

Fig. 8 Sustained release of aldreonate from composite microparticles. ${ }^{85}$

Free radical polymerisation, reversible addition-fragmentation chain transfers (RAFT), and emulsion polymerisation can be utilised to form various target specific and cell specific delivery systems using MSNs. However, as evident from Fig. 9, the drug was loaded after the polymer was coated onto the mesoporous silica, which led to poor drug loading into mesopores compared to methods like $\mathrm{S} / \mathrm{O} / \mathrm{W}$. In more recent methods, the drug is loaded into the mesopores prior to polymer coating, and the polymer is coated onto them. The latter suffers from water soluble molecules leaking into the continuous phase, leading to poor drug loading. Hence, there is a need to develop a system that can offer the dual advantage of higher loading efficiency and effective functional coating for targeting.

\section{Enzyme immobilisation}

Enzymatic bioprocesses have the major advantages of high selectivity and yield compared to chemical synthesis routes. These processes have been widely used in many industries, for example in the production of ammonium acrylate, and the removal of heavy metals from wastewater. ${ }^{155,156}$ They are also applied in the synthesis of fructose from starch in the food industry ${ }^{157}$ and production of 6-aminopenicillanic acid (APA) in the pharmaceutical industry. ${ }^{158}$ The main obstacle for these processes to be industrially feasible is the high cost of enzyme production. ${ }^{155}$

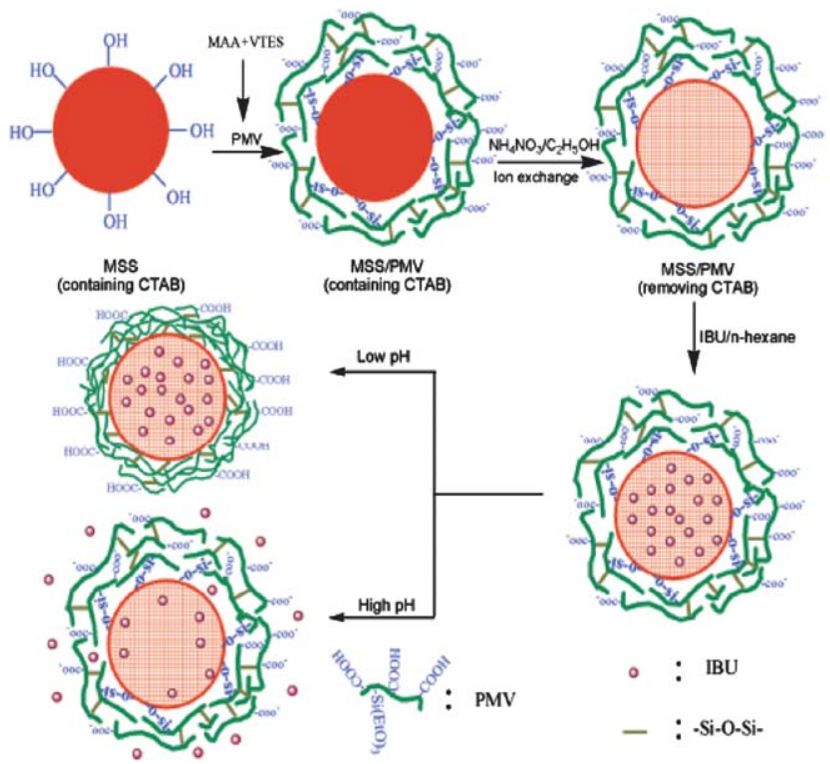

Fig. 9 Novel synthesis strategy to coat PMV onto Mesoporous silica. ${ }^{124}$ 
An unbound (free) enzyme usually has low stability towards heat, organic solvents, acids or bases and its recovery is difficult. In addition, the expense of producing this makes it less an option as an industrial catalyst compared to other chemical catalysts. Futhermore, enzymes have highly controlled regio-, stereo- and substrate-specificity. The enzymatic reactions generally proceed under very mild conditions. It is thus highly desirable to improve enzyme stability and reusability. Ultimately, this will help reduce enzyme production costs. ${ }^{70,159}$ Techniques to improve enzyme stability include enzyme immobilisation, enzyme modification, protein engineering and medium engineering. Enzyme immobilisation can attach an enzyme on the surface or inside the pore of a solid carrier. ${ }^{159,160,161}$

Enzyme immobilisation can be conducted through physical or chemical adsorption onto solid supports and via physical entrapment or encapsulation within a polymer network. ${ }^{155,162-164}$ Adsorption is a simple and inexpensive method however enzyme leakage is a problem. Entrapment or encapsulation is a good way to prevent direct contacts between enzymes and a harsh environment; however these methods have drawbacks of mass transfer limitation and low enzyme loading. ${ }^{163}$

A wide range of enzymes have been immobilised onto various mesoporous silica materials (Table 2). This section will summarise the studies of enzyme immobilisation onto mesoporous silica materials.

\subsection{Mesoporous silica materials as supporting agents for enzyme immobilisation}

Balkus et al. reported lysozyme immobilisation within MCM-41 matrices. This study highlighted the importance of silica pore size to encapsulate the enzyme. But, MCM-41 could not encapsulate a biomolecule with a size greater than $40 \mathrm{kDa} \cdot{ }^{165,166}$ On the other hand, SBA-15 with larger pore sizes $(5-30 \mathrm{~nm})^{\mathbf{1 6 7}}$ opened wider possibilities to encapsulate various larger proteins. However, SBA-15 materials (pore sizes $6.8 \mathrm{~nm}$ ) showed a small adsorption amount of larger protein such as bovine serum albumin. ${ }^{\mathbf{1 6 8}}$

Sun et al. was able to perform highly accelerated lysozymes adsorption by enlarging the conventional SBA-15 pore. They created ordered large mesopores with a pore size of $13 \mathrm{~nm}$. Adsorption of enzymes reached equilibrium after $10 \mathrm{~min}$ as compared to hours for the conventional SBA-15. They could also confirm that most of the lysozymes were within the pores. ${ }^{169} \mathrm{Liu}$ et al. reported the fabrication of silica hollow spheres with highly ordered hexagonal arrangement of the mesopore in the shell via a simple $\mathrm{O} / \mathrm{W}$ (2,2,4-trimethylpentane (TMP)/water) emulsion template method in the presence of $(\mathrm{EO})_{20}(\mathrm{PO})_{70}(\mathrm{EO})_{20}$ under buffer solution ( $\mathrm{NaAc}-\mathrm{HAc}, \mathrm{pH}=4.4)$ using tetramethoxysilane (TMOS) as a silica source. The mesoporous silicas exhibited a high adsorption capacity (up to $536 \mathrm{mg} \mathrm{g}^{-1}$ ) and very rapid ( $<5$ min to reach equilibrium) lysozyme immobilisation. More importantly, it was revealed that mesoporous silica hollow spheres with rugged surfaces can greatly accelerate the enzyme adsorption rate during the adsorption process. ${ }^{170}$

Fan et al. successfully synthesised ordered large pore cubic mesoporous silica (FDU-12) with pore sizes up to $27 \mathrm{~nm}$. This cubic structure displayed better performance compared to the 2-D structure (MCM-41, SBA-15) in terms of pore blockage. ${ }^{45,171}$ The main advantage of larger pore sizes is the efficient mass transfer of the guest molecules within the porous network. FDU12 mesoporous silica materials certainly offer wider applications for bio-molecule encapsulation. We recently synthesised ordered functionalised cubic FDU-12 mesoporous silica with a cavity size of $25.4 \mathrm{~nm}$ and entrance size of $10.5 \mathrm{~nm}$ (Fig. 10). These silicas have been used to study the immobilisation of large cellulase enzymes. We found that around $50 \%$ of the enzymes were successfully loaded into the pore. ${ }^{112}$

Enzyme immobilisation must focus on achieving high enzyme stability. The stability can be divided into operational stability and storage stability. Operational stability indicates the capability of the enzymes to maintain their activity, while storage stability is related to the performance of the immobilised system in avoiding enzyme release. The main concern of enzyme immobilisation is loss of enzyme activity over time. The reduction is caused by many factors: pore diffusion resistance, low substrate mass transfer, paralysed enzyme active sites and limited enzyme mobility. ${ }^{172,173}$

\subsection{Enzyme activity on mesoporous silica materials}

Improving the geometrical structure of silica supports through pore enlargement is one of the popular methods to minimise diffusion resistance. Pore size affects not only the extent of enzyme immobilisation but also enzymatic activity. Lu et al. confirmed that when comparing pore size, pore volume, mesophase and surface area of the mesoporous materials, pore size had a greater effect on immobilised enzyme activity. ${ }^{174}$ Additionally, it is necessary to strengthen the bonding between the enzymes and the supports. Introducing functional groups into supporting material surface can improve enzyme-support interactions and reduce leakage of immobilised enzymes. ${ }^{70}$

Interestingly, Lei et al. showed from their research that immobilised enzymes within the functionalised mesoporous silica had a doubled activity compared to free enzymes. ${ }^{175}$ Chong et al. proved that the activity of immobilised penicillin $G$ acylase (PGA) within vinyl-functionalised mesoporous silica support was higher than free PGA. ${ }^{172}$ These results indicated that immobilised enzymes can perform better when enzymes were immobilised in the right supporting materials.

Park et al. reported lysosyme immobilisation within different supports: SBA-15 and PMOs. They made three different PMOs by using three different precursors: BTMS-amine, BTESbenzene and BTES-phenyl. This study confirmed the significant influence of a solution's $\mathrm{pH}$ in protein adsorption. At $\mathrm{pH}$ near the $\mathrm{pI}$, because of hydrophobic surface, silica can reach an optimum loading amount. ${ }^{119}$ At this $\mathrm{pH}$, the electrostatic repulsion effect among the proteins was minimised and thus the protein can be arranged in a more compact construction.

One of the prominent properties of mesoporous silica is the abundant silanol groups on their surface. These silanol groups are highly reactive and hence can be used to attach several functional groups on the surface of silica. The surface modification increases the affinity between enzymes and supporting materials. It has been found that retention of immobilised enzyme activity is strongly influenced by surface chemistry of the supporting materials. ${ }^{\mathbf{1 7 6}}$

Chong et al. studied immobilisation of penicillin $\mathrm{G}$ acylase (PGA) into functionalised SBA-15 like mesoporous silica materials. Different organosilanes were used for functionalisation: 

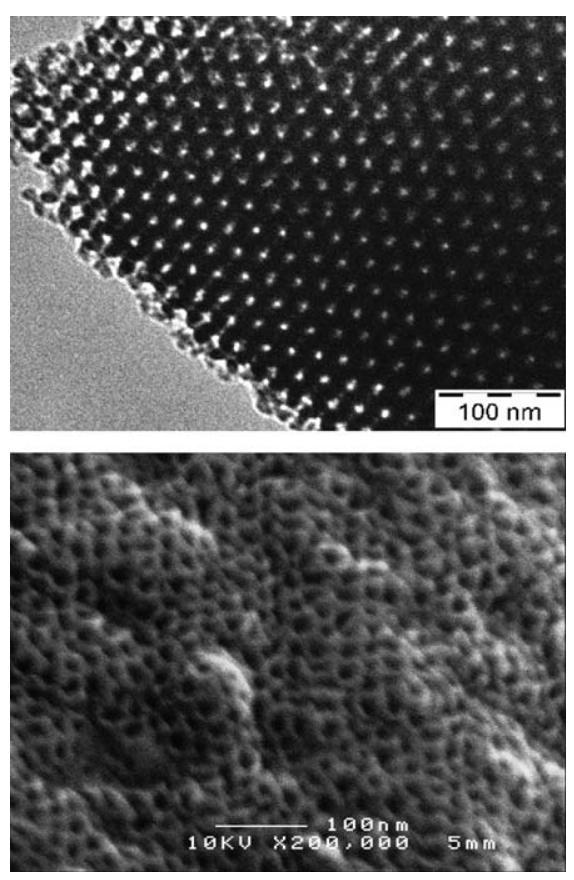

Fig. 10 High resolution of TEM and SEM images of very large pore Amine functionalised FDU-12 materials. ${ }^{12}$

3-aminopropyltriethoxysilane (APTES), 3-mercaptopropyltrimethoxysilane (MPTMS), phenyltri-methoxysilane (PTMS), vinyltriethoxysilane (VTES) and 4-(triethodysilyl)butyronitrile (TSBN). Further, they modified APTES-SBA-15 with a crosslinking agent called gluteraldehyde. Most of the functionalised samples had a higher PGA adsorption amount compared to nonfunctionalised silica. They found that vinyl group functionalised silica was very effective functionally for adsorption and stability of PGA.

Vinyl functionalised silica enabled the enzyme to maintain a stable conformation structure and a flexible mobility of the active sites. As a result, the immobilised enzymes maintained a high activity. ${ }^{172}$ Many researchers have used gluteraldehyde to crosslink aminopropyl functionalised MSNs to immobilise PGA. Results showed that the covalent bond interactions could improve the stability of immobilised PGA. ${ }^{172,177}$

In contrast, some researchers believed that enzyme immobilisation through covalent bonding using a cross linking agent such as glutaraldehyde may cause a reduction in immobilised enzyme activity. The bonding could cause a conformational change of enzymes, which affects enzyme's flexibility and mobility to convert the substrate. ${ }^{179,180}$ In this case, it was preferable to use non-covalent bonding, such as physical adsorption, electrostatic interactions, hydrophobic interactions, etc. PGA has been also immobilised on the APTES functionalised SBA-15. ${ }^{181}$ Interestingly, the mesoscopic order of the SBA-15 can be maintained even after the immobilisation of PGA. The author used a grafting method for amine functionalisation of SBA-15 as the cocondensation method resulted in disordered structure. ${ }^{69}$ The loading amount of the PGA was $68 \mathrm{mg} \mathrm{g}^{-1}$ of amine-functionalised SBA-15. It can maintain $73 \%$ activity of its free form. ${ }^{181}$

Our recent study showed the importance of organic functionalisation (amine, vinyl, thiol and phenyl) of a silica supporting material for enzyme immobilisation and activity maintenance. ${ }^{177}$ The functionalisation affected the protein (BSA and cellulase enzymes) adsorbed amount and enzyme activity. Vinyl functionalised silica (S-VTMS) had a promising result, which demonstrated a high performance in enzyme immobilisation and enzyme activity as well as enzyme stability. Vinyl organosilane introduced hydrophobicity to the silica surface, which increased the silica surface's affinity against the proteins (BSA and cellulase enzyme). The vinyl mesoporous silicas were able to maintain the enzyme activity. In contrast, amine functionalised mesoporous silica (APTES) showed the highest adsorption amount yet with low activity of immobilised cellulase. The amine functionalisation induced electrostatic interactions between the amine terminal groups of mesoporous silica and carboxylic acids from the enzyme's active sites. As a result, the immobilised cellulase had a low activity ${ }^{\mathbf{1 8 2}}$

The aforementioned methods to attach or immobilise enzymes on the surface of silica face a challenge of enzyme release in biological conditions. The leaking of immobilised enzymes depends on the bonding strength between the enzymes and the silica. Yang et al. used a different approach to immobilise enzymes (fumarase, trypsin, lipase and PLE) using the one pot synthesis method. In this process, enzymes were encapsulated during synthesis of ordered mesoporous silica ('fish in net') (Fig. 11), thus the enzymes were entrapped within the macroporous cage that was formed during the synthesis. ${ }^{178}$ The authors claimed that all of the immobilised enzymes had high activity and stability and this method might be applied to other types of enzymes. Yet one must be cautious with the effects of silica synthesis condition ( $\mathrm{pH}$, chemical substances, etc), which might also affect enzyme activity. Due to small pore entrances of the larger pored MSNs, they are more susceptible to blockages. Therefore, the enlarged pore entrance would result in an increase

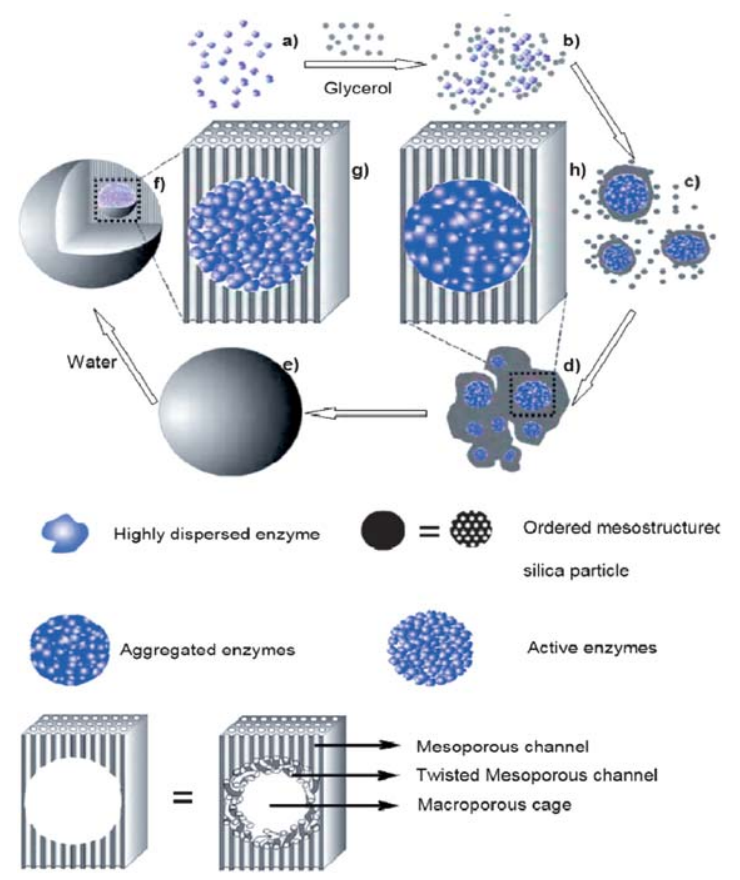

Fig. 11 The 'Fish in Net' method to encapsulate enzymes within the silica network. ${ }^{178}$ 
in loading and mass transfer. The latest report from the Magner group showed the utilisation of the unique metal-enzyme interaction for enzyme immobilisation. ${ }^{183}$ This group immobilised His6-tagged protein onto nickel(II)-cyclam grafted SBA-15 mesoporous silica. They showed that the protein and the support interacted through nickel coordination. This was a result of interactions between the $\mathrm{Ni}^{2+}$ and the imidazole rings of the His6tag. No desorption was found from their leaching study. Previous reports showed that this type of interaction had advantages of high stability, high enzymatic activity and reusability. ${ }^{12,184-186}$ Another distinctive approach for enzyme immobilisation used surface-based click chemistry route. ${ }^{187,188}$ Bein et al. studied the immobilisation of trypsin within mesoporous SBA 15 material using the 'click reaction'. Azide functionalised SBA-15 reacted with acetylene modified trypsin in a copper(I) catalysed Huisgen reaction. Furior Transformed Infrared Spectroscopy (FTIR), nitrogen sorption and Thermogravimetric Analysis (TGA) confirmed the trypsin immobilisation. The resulted immobilised trypsin showed retention of enzyme activity and stability. No desorption was found under the experimental conditions. ${ }^{75}$

\section{Conclusion \& outlook}

In the past decade, there has been an intense focus on mesoporous silica nanoparticle based systems with an accurately predictable delivery. Many systems have been designed to target cancer cells with some very promising results. However, only limited reports focus on the actual formulation parameters such as dosage forms, route of administration, stability, and storage of final formulation using MSNs in a biological system. ${ }^{203}$ Despite promising demonstration of MSN as drug delivery carriers, there are some critical issues that need to be addressed to effectively utilise MSN in biomedicine. Additionally, physiological interactions between MSN and biointerfaces (enzyme, cells, receptors, blood brain barrier etc) need careful attention. Detailed understanding of surface functional groups and its effects in vivo is a critical component in this process.

Recently, He et al. showed that MCM-41 can be completely degraded in 15 days in $0.5 \mathrm{ppm}$ SBF solution at physiological conditions. ${ }^{204}$ They revealed for the first time the three-stage degradation behaviour of MSNs and showed that it was greatly dependent on the initial concentration and specific surface area of MCM-41. Moreover, a recent finding showed that MSNs based tablet dosage form showed some forms of dissolution in simulated gestric fluid (SGF), which has not been shown before. ${ }^{205}$ These recent findings suggest that the release from the unfunctionalised MSNs is not only dependent on diffusion of drugs from the mesopores, but also on dissolution of silica nanoparticles. Hence, the development of in vivo biodegradation and biodistribution models would be highly required in order to completely understand the bio-behaviour of these nanoparticles.

Using MSNs as a diluent and filler was identified when $\mathrm{Xu}$ et al. first reported the use of SBA-15 to make tablets. This opened up a whole new area of application with these types of materials. ${ }^{206}$ Tablets and capsules are one of the most widely used dosage forms to deliver therapeutics to the human body. It will be interesting to see the role of mesoporous silica for selectively targeting body organs such as stomach, small intestine, colon, rectum, and brain using these conventional delivery systems.

As shown in the previous sections, many bioapplications exist for mesoporous silicas. Many of these applications involve the use of mesoporous silica material as a control delivery vehicle of different biomolecules and how they are actively taken up in the body. However, there is a limitation such as the pore size, which results in the size of chemical moiety being restricted to a certain size range. For delivery into cells, it has been shown that the particles need to be small so that there is effective cellular uptake. Large particles cannot be used for these types of application. In contrast, these large pore particles can be used for enzymatic processes to entrap and reuse the enzymes thus reducing the cost. Future research related to material synthesis will be very much directed towards preparation and evaluation of highly ordered, small size and large pore MSNs. The extra large pore size (20-50 $\mathrm{nm}$ ) will facilitate immobilisation of a broader range of enzymes and increase the application of these materials in various areas including bioanalysis, biotechnology, bioprocessing, food and environmental systems.

For applications such as the delivery of drugs, vaccines, RNA and DNA, conclusive cytotoxicity tests need to be performed for each application and cell line. Currently there are many conflicting reports but there is a general consensus that MSNs are relatively safe for delivery at low dosages and particle size ranging 50-400 nm can ensure maximum uptake from the cells. Long-term cytotoxicity tests also need to be performed to ensure their clinical safety. Further studies in degradation, how the silica is excreted or broken down in the body, also need to be examined. However, once this has been done, MSNs do appear to be excellent candidates for bioapplications.

Another great property of MSNs is the use of silica as a coating for smaller particles such as magnetic particles and quantum dots (QDs). On their own, magnetic particles and QDs are toxic, but coating with a silica layer makes them more biocompatible. The resulting composite particles are thus excellent candidates for in vivo imaging such as magnetic resonance imaging. The ease at which the surface of MSNs can be functionalised allows for an abundant array of new novel applications in a variety of fields. The challenging goal is to track these nanoparticles not only to site of action but throughout its biodistribution and excretion. This will ensure the long term safety of these nanoparticles in the human body.

A new family of magnetic mesoporous silica has also been exploited for enzyme immobilisation, which shows promising results. However, enzyme immobilisation must focus on achieving high enzyme stability. It is expected that immobilised enzymes have a high enzyme activity and minimum enzyme desorption (leaching). However, literature citing this is unfortunately very limited and further studies on this area are highly desired.

Due to its unique characteristics, MSNs can also be useful in other industries, for example agrochemical, where it can be used for pesticide storage and delivery in a predictable manner. MSN based encapasulation and delivery of pesticides could have some positive environmental implications as well as decreasing the extermination of non-target insects. The latest developments in mesoporous silica synthesis have produced various materials with very large pores and unique morphology. Lastly, the quest 
for intelligent nanomedicine based upon MSNs and its detailed in vitro and in-vivo testing is one of the most important areas of research in recent times and will be in near future.

\section{Acknowledgements}

The support of the Australian Research Council both through the Discovery Project Scheme (DP1095861, DP1094070, and DP0987969) and Linkage Project Scheme (LP0882681) is gratefully acknowledged.

\section{References}

1 Z. P. Xu and G. Q. M. Lu, Pure Appl. Chem., 2006, 78, 1771-1779.

2 S. B. Kaye and V. J. Richardson, Cancer Chemotherapy and Pharmacology, 1998, 3, 81-85.

3 K. S. Soppimatha, T. M. Aminabhavi, A. R. Kulkarnia and W. E. Rudzinsk, J. Controlled Release, 2001, 70, 1-20.

4 C. T. Kresge, M. E. Leonowicz, W. J. Roth, J. C. Vartuli and J. S. Beck, Nature, 1992, 359, 710-712.

5 D. Zhao, J. Feng, Q. Huo, N. Melosh, G. H. Fredrickson, B. F. Chmelka and G. D. Stucky, Science, 1998, 279, 548-552.

6 S. A. Bagshaw, E. Prouzet and T. J. Pinnavaia, Science, 1995, 269, $1242-1244$

7 R. Ryoo, J. M. Kim, C. H. Ko and C. H. Shin, J. Phys. Chem., 1996, 100, 17718-17721.

8 Y. Han and J. Y. Ying, Angew. Chem., Int. Ed., 2005, 44, 288-292.

9 Q. Huo, D. I. Margolese, U. Ciesla, P. Feng, T. E. Gier, P. Sieger, R. Leon, P. M. Petroff, F. Schuth and G. D. Stucky, Nature, 1994, 368, 317-321.

10 M. Liong, S. Angelos, e. Choi, k. Patel, J. F. Stoddart and J. I. Zink, J. Mater. Chem., 2009, 19, 6251.

11 I. I. Slowing, J. L. vivero-Escoto, Chia-Wen and V. S.-Y. Lin, $A d v$. Drug Delivery Rev., 2008, 60, 1278-1288.

12 C.-H. Lee, T.-S. Lin and C.-Y. Mou, Nano Today, 2009, 4, 165-179.

13 M. Vallet-Regi, F. balas and D. Arcos, Angew. Chem., Int. Ed., 2007, 46, 7548-7558.

14 S. giri, B. G. Trewyn and V. S. Lin, Nanomedicine, 2007, 2, 99-111.

15 K. K. Coti, M. E. Belowich, M. Liong, M. W. Ambrogio, Y. A. Lau, H. A. Khatib, J. I. Zink, N. M. Khashab and J. F. Stoddart, Nanoscale, 2009, 1, 16-39.

16 J. M. Rosenholm, C. Sahlgren and M. Linden, Nanoscale, 2010, 2 , 1870.

17 I. I. Slowing, J. L. Vivero-Escoto, B. G. Trewyn and S.-Y. L. Victor, J. Mater. Chem., 2010, 20, 7924-7937.

18 A. Kumaria, S. K. Yadava and S. C. Yadav, Colloids Surf., B, 2009, 75, $1-18$.

19 K. M. Kitchens and H. Ghandehari, Nanotechnology in Drug Delivery, 2009, 423-459.

20 T. D. Madden, G. Adlakha-Hutcheon, M. B. Bally and C. R. Shew, Nat. Biotechnol., 1999, 17, 775-779.

21 K. CT, L. ME, R. WJ and V. JC, J. Am. Chem. Soc., 1992, 114, 10834-10843.

22 Q. Cai, Z.-S. Luo, W.-Q. Pang, Y.-W. Fan, X.-H. Chen and F.Z. Cui, Chem. Mater., 2001, 13, 258-263.

23 Z. Ji, K. T. Lee, M. Mnjauze and L. F. Nazar, Chem. Commun., 2008, 4288-4290.

24 T.-W. Kim, I. I. Slowing, P.-W. Chung and V. S.-Y. Lin, ACS Nano, 2010.

25 T.-W. Kim, F. Kleitz, B. Paul and R. Ryoo, J. Am. Chem. Soc., 2005, 127, 7601

26 T.-W. Kim and L. A. Solovyov, J. Mater. Chem., 2006, 16, 1445.

27 K. Schumacher, P. I. Ravikovitch, A. D. Chesne, A. V. Neimark and K. K. Unger, Langmuir, 2000, 16, 4648-4654.

28 K. Schumacher, M. Grün and K. K. Unger, Microporous Mesoporous Mater., 1999, 27, 201-206.

29 J. Liu, S. Z. Qiao, S. Budi Hartono and G. Q. Lu, Angew. Chem., Int. Ed., 2010, 49, 4981-4985.

30 T.-W. Kim, P.-W. Chung and V. S.-Y. Lin, Chem. Mater., 2010, 22, 5093-5104.

31 H. Djojoputro, X. F. Zhou, S. Z. Qiao, L. Z. Wang, C. Z. Yu and G. Q. Lu, J. Am. Chem. Soc., 2006, 128, 6320-6321.
32 S. Z. Qiao, C. X. Lin, Y. Jin, Z. Li, Z. Yan, Z. Hao, Y. Huang and G. Q. Lu, J. Phys. Chem. C, 2009, 113, 8673-8682.

33 C. X. C. Lin, S. Z. Qiao, C. Z. Yu, S. Ismadji and G. Q. m. Lu, Microporous Mesoporous Mater., 2009, 117, 213-219.

34 J. Liu, S. B. Hartono, Y. G. Jin, Z. Li, G. Q. Lu and S. Z. Qiao, J. Mater. Chem., 2010, 20, 4595-4601.

35 J. Gao, G. Liang, J. S. Cheung, Y. Pan, Y. Kuang, F. Zhao, B. Zhang, X. Zhang, E. X. Wu and B. Xu, J. Am. Chem. Soc., 2008, 130, 11828-11833.

36 D. Niu, Z. Ma, Y. Li and J. Shi, J. Am. Chem. Soc., 2010, 132, 15144-15147.

37 M. Manzano, V. Aina, C. O. Arean, F. Balas, V. Cauda, M. Colilla, M. R. Delgado and M. Vallet-regi, Chem. Eng. J., 2008, 137, 30-37.

38 F. Qu, G. Zhu, S. Huang, S. Li, J. Sun, D. Zhang and S. Qiu, Microporous Mesoporous Mater., 2006, 92, 1-9.

39 L. Zhang, S. Qiao, Y. Jin, L. Cheng, Z. Yan and G. Q. Lu, Adv. Funct. Mater., 2008, 18, 3834-3842.

40 H. Hata, S. Saeki, T. Kimura, Y. Sugahara and K. Kuroda, Chem. Mater., 1999, 11, 1110-1119.

41 F. Qua, G. Zhua, H. Lina, W. Zhanga, J. Suna, S. Lia and S. Qiu, J. Solid State Chem., 2006, 179, 2027-2035.

42 R. Mellaerts, C. A. Aerts, J. V. Humbeeck, P. Augustijns, G. V. d. Mooterc and J. A. Martens, Chem. Commun., 2007, 13751377.

43 Q. Tanga, Y. Xua, D. Wua, Y. Suna, J. Wangb, J. Xub and F. Dengc, J. Controlled Release, 2006, 114, 41-46.

44 T. Azais, C. Tourne-Peteilh, F. Aussenac, N. Baccile, C. Coelho, J.m. Devoisselle and F. babonneau, Chem. Mater., 2006, 18, 63826390.

45 J. Fan, C. Yu, J. Lei, Q. Zhang, T. Li, B. Tu, W. Zhou and D. Zhao, J. Am. Chem. Soc., 2005, 127, 10794-10795.

46 L. Chen, G. Zhu, D. Zhang, H. Zhao, M. Guo, W. Shi and S. Qiu, J. Mater. Chem., 2009, 19, 2013-2017.

47 Q. Gao, Y. Xu, D. Wu, y. Sun and X. Li, J. Phys. Chem. C, 2009, 113, 12753-12758.

48 Y.-J. Han, G. D. Stucky and A. Butler, J. Am. Chem. Soc., 1999, 121, 9897-9898.

49 A. Wang, M. Liu, H. Wang, C. Zhou, Z. Du, S. Zhu, S. Shen and P. Ouyang, J. Biosci. Bioeng., 2008, 106, 286-291.

50 A. Katiyar and Neville G. Pinto, Small, 2006, 2, 644-648.

51 L. Zhang, S. Qiao, Y. Jin, H. Yang, S. Budihartono, F. Stahr, Z. Yan, X. Wang, Z. Hao and G. Q. Lu, Adv. Funct. Mater., 2008, 18, 3203-3212.

52 F. Gao, P. Botella, A. Corma, J. Blesa and L. Dong, J. Phys. Chem. $B, 2009,113,1796-1804$.

53 M. Fujiwara, F. Yamamoto, K. Okamoto, K. Shiokawa and R. Nomura, Anal. Chem., 2005, 77, 8138-8145.

54 F. Torney, B. G. Trewyn, V. S.-Y. Lin and K. Wang, Nat. Nanotechnol., 2007, 2, 295-300.

55 S. M. Solberg and C. C. Landry, J. Phys. Chem. B, 2006, 110, 1526115268.

56 W. Xua, Q. Gaoa, Y. Xua, D. W. Suna, W. Shenb and F. Dengb, Powder Technol., 2009, 192, 13-20.

57 B. G. Trewyn, I. I. Slowing, S. Giri, H.-T. Chen and V. S.-Y. Lin, Acc. Chem. Res., 2007, 40, 846-853.

58 F. Hoffmann, M. Cornelius, J. Morell and M. Froba, Angew. Chem., Int. Ed., 2006, 45, 3216-3251.

59 N. K. Mal, M. Fujiwara and Y. Tanaka, Nature, 2003, 421, 350-353.

60 K. Patel, S. Angelos, W. R. Dichtel, A. Coskun, Y.-W. Yang, J. I. Zink and J. F. Stoddart, J. Am. Chem. Soc., 2008, 130, 23822383.

61 C.-Y. Lai, B. G. Trewyn, D. M. Jeftinija, K. Jeftinija, S. Xu, S. Jeftinija and V. S.-Y. Lin, J. Am. Chem. Soc., 2003, 125, 44514459 .

62 A. Bernardos, E. Aznar, C. Coll, R. Martinez-Manez, J. M. Barat, M. D. Marcos, F. Sancenon, A. Benito and J. Soto, J. Controlled Release, 2008, 131, 181-189.

63 J. C. Doadrio, E. M. B. Sousa, I. Izquierdo-Barba, A. L. Doadrio, J. Perez-Pariente and M. Vallet-Regi, J. Mater. Chem., 2006, 16, $462-466$.

64 J. Lu, M. Liong, J. I. Zink and F. Tamanoi, Small, 2007, 3, 13411346.

65 E. Aznar, M. D. Marcos, R. Manrtinez-Manez, F. Sancenon, J. Soto, P. Amoros and C. Guillem, J. Am. Chem. Soc., 2009, 131, $6833-6843$ 
66 F. Bala, M. Manzano, M. Colilla and M. Vallet-Regi, ActaBiomaterialia, 2008, 4, 514-522.

67 F. Bala, M. Manzano, P. Horcajada and M. Vallet-Regi, J. Am. Chem. Soc., 2006, 128, 8116-8817.

68 L. Chenghong, Y. Shin, J. K. Magnuson, G. Fryxell, L. L. Lasure, D. C. Elliott, J. Liu and E. J. Ackerman, Nanotechnology, 2006, 17, 5531.

69 A. S. M. Chong and X. S. Zhao, J. Phys. Chem. B, 2003, 107, 1265012657.

70 A. S. M. Chong and X. S. Zhao, Applied Surface Science, 2004, 237, 398-404.

71 M. Manzano, V. Aina, C. O. Aréan, F. Balas, V. Cauda, M. Colilla, M. R. Delgado and M. Vallet-Regí, Chem. Eng. J., 2008, 137, 30-37.

72 A. Neito, F. Bala, M. Colilla, M. Manzano and M. Vallet-Regi, Microporous Mesoporous Mater., 2008, 116, 4-13.

73 T. P. B. Nguyen, J.-W. Lee, W. G. Shim and H. Moon, Microporous Mesoporous Mater., 2008, 110, 560-569.

74 C. Kim, C. Park, K. Oh and S. C. Lee, Angew. Chem., Int. Ed., 2007, 46, $1455-1457$.

75 A. Schlossbauer, D. Schaffert, J. Kecht, E. Wagner and T. Bein, $J$. Am. Chem. Soc., 2008, 130, 12558-12559.

76 T. Xia, M. Kovochich, M. Liong, H. Meng, S. Kabehie, S. George, J. I. Zink and A. E. Nel, ACS Nano, 2009, 3, 3273-3286.

77 C. Yague, M. Moros, V. Grazu, M. Arruebo and J. Sanatamaria, Chem. Eng. J., 2008, 137, 45-53.

78 X. Zhang, R.-F. Guan, D.-Q. Wu and K.-Y. Chan, J. Mol. Catal. B: Enzym., 2005, 33, 43-50.

79 J. Lu, M. Liong, S. Sherman, T. Xia, M. Kovochich, A. E. Nel, J. I. Zink and F. Tamanoi, NanoBiotechnology, 2007, 3, 89-95.

80 M. Vallet-Regi, A. Ramila, R. P. d. Real and J. Perez-Pariente, Chem. Mater., 2001, 13, 308-311.

81 Q. Tang, Y. Xu, D. Wu and Y. Sun, Chem. Lett., 2006, 35, 474-475.

82 Y. Zhao, B. G. Trewyn, I. I. Slowing and V. S.-Y. Lin, J. Am. Chem. Soc., 2009, 131, 3462-3463.

83 S. Angelos, E. Choi, F. Vogtle, L. d. Cola and J. I. Zink, J. Phys. Chem. C, 2007, 111, 6589-6592.

84 S. Angelos, N. M. Khashab, Y.-W. yang, A. Trabolsi, H. A. Khatib, J. F. Stoddart and J. I. Zink, J. Am. Chem. Soc., 2009, 131, 1291212914.

85 X. Shi, Y. Wang, R. R. Varshney, L. Ren, F. Zhang and D.A. Wang, Biomaterials, 2009, 30, 3996-4005.

86 J. 1. Vivero-Escoto, I. I. Slowing, C.-W. Wu and V. S.-Y. Lin, J. Am. Chem. Soc., 2009, 131, 3462-3463.

87 A. S. M. Chong and X. S. Zhao, Applied Surface Science, 2004, 237, 398-404.

88 A. Katiyar, L. Ji, P. Smirniotis and N. G. Pinto, J. Chromatogr., A, 2005, 1069, 119-126.

89 A. Vinu, V. Murugesan, O. Tangermann and M. Hartmann, Chem. Mater., 2004, 16, 3056-3065.

90 H. Essa, E. Magner, J. Cooney and B. K. Hodnett, J. Mol. Catal. B: Enzym., 2007, 49, 61-68.

91 J. Ho, M. K. Danquah, H. Wang and G. M. Forde, J. Chem Technol. Biotechnol., 2008, 83, 351-358.

92 C.-y. Hong, Z. Li and C.-Y. Pan, Eur. Polym. J., 2007, 43, 4114 4122.

93 J. M. Rosenholm, A. Meinander, E. Peuhu, R. Neimi, J. E. Eriksson, C. Sahlgren and M. Linden, ACS Nano, 2009, 3, 197-206.

94 J. M. Rosenholm and M. Linden, J. Controlled Release, 2008, 128, $157-164$.

95 A. M. Chen, M. Zhang, D. Wei, D. Stueber, O. Taratula, T. Minko and H. He, Small, 2009, 5, 2673-2677.

96 I. Y. Park, I. Y. Kim, M. K. Yoo, Y. J. Choi, M.-H. Cho and C. S. Cho, Int. J. Pharm., 2008, 359, 280-287.

97 L. P. Mercuri, L. V. Carvalho, F. A. Lima, C. Quayle, M. C. A. Fantini, G. S. Tanaka, W. H. Cabrera, M. F. D. Furtado, D. V. Tambourgi, J. R. Matos, M. Jaroniec and O. A. Sant'Anna, Small, 2006, 2, 254-256.

98 J. Ho, Y. Huang, M. K. Danquah, H. Wang and G. M. Forde, Eur. J. Pharm. Sci., 2010, 39, 412-420.

99 J. S. Chang, K. L. Chang, D. F. Hwang and Z. L. Kong, Environ Sci. Technol., 2007, 41, 2064-2068.

100 A. J. Di Pasqua, K. K. Sharma, Y.-L. Shi, B. B. Toms, W. Ouellette, J. C. Dabrowiak and T. Asefa, J. Inorg. Biochem., 2008, 102, 1416-1423.

101 J. Yu, H. Zhao, L. Ye, H. Yang, S. Ku, N. Yang and N. Xiao, J. Mater. Chem., 2009, 19, 1265-1270.
102 Z. Tao, B. B. Toms, J. Goodisman and T. Asefa, Chem. Res. Toxicol., 2009, 22, 1869-1880.

103 M. J. K. Thomas, I. Slipper, A. Walunj, A. Jain, M. E. Favretto, P. Kallinteri and D. Douroumis, Int. J. Pharm., 2010, 387, 272277.

104 T. Heikkilä, H. A. Santos, N. Kumar, D. Y. Murzin, J. Salonen, T. Laaksonen, L. Peltonen, J. Hirvonen and V.-P. Lehto, Eur. J. Pharm. Biopharm., 2010, 74, 483-494.

105 D.-M. Huang, T.-H. Chung, Y. Hung, F. Lu, S.-H. Wu, C.-Y. Mou, M. Yao and Y.-C. Chen, Toxicol. Appl. Pharmacol., 2008, 231, 208215.

106 Y. Zhao, B. G. Trewyn, I. I. Slowing and V. S. Y. Lin, J. Am. Chem. Soc., 2009, 131, 8398-8400.

107 M. Fisichella, H. Dabboue, S. Bhattacharyya, M.-L. Saboungi, J.P. Salvetat, T. Hevor and M. Guerin, Toxicol. in Vitro, 2009, 23, 697-703.

108 J. L. Vivero-Escoto, I. I. Slowing and V. S. Y. Lin, Biomaterials, 2010, 31, 1325-1333.

109 H. Vallhov, S. Gabrielsson, M. Strømme, A. Scheynius and A. E. Garcia-Bennett, Nano Lett., 2007, 7, 3576-3582.

110 D. Napierska, L. C. J. Thomassen, V. Rabolli, D. Lison, L. Gonzalez, M. Kirsch-Volders, J. A. Martens and P. H. Hoet, Small, 2009, 5, 846-853.

111 H. Qianjun, Z. Zhiwen, G. Yu, S. Jianlin and L. Yaping, Small, 2009, 5, 2722-2729.

112 S. Hartono, S. Qiao, K. Jack, B. P. Ladewig, Z. Hao and G. Lu, Langmuir, 2009, 25, 6413-6424.

113 Q. He, J. Shi, F. Chen, M. Zhu and L. Zhang, Biomaterials, 2010, 31, 3335-3346.

114 Z.-Z. Chen, Y.-M. Li, X. Peng, F.-R. Huang and Y.-F. Zhao, J. Mol. Catal. B: Enzym., 2002, 18, 243-249.

115 Y.-S. Lin and C. L. Haynes, Journal of the American Chemical Society, 132, pp. 4834-4842.

116 Y. Chen, H. Chen, L. Guo, Q. He, F. Chen, J. Zhou, J. Feng and J. Shi, ACS Nano, 2009, 4, 529-539.

117 Q. He, J. Zhang, J. Shi, Z. Zhu, L. Zhang, W. Bu, L. Guo and Y. Chen, Biomaterials, 2010, 31, 1085-1092.

118 S. P. Hudson, R. F. Padera, R. Langer and D. S. Kohane, Biomaterials, 2008, 29, 4045-4055.

119 M. Park, S. S. Park, M. Selvaraj, D. Zhao and C.-S. Ha, Microporous Mesoporous Mater., 2009, 124, 76-83.

120 J. S. Souris, C.-H. Lee, S.-H. cheng, C.-T. chen, C.-S. Yang, J. A. Ho, C.-Y. Mou and L.-w. Lo, Biomaterials, 2010, 31, 55645574.

121 C. Park, K. Oh, S. C. Lee and C. Kim, Angew. Chem., Int. Ed., 2007, 46, 1455-1457.

122 A. Bernardos, E. Aznar, M. d. Marcos, R. Martinez-Manzen, F. Sancenon, J. Soto, J. M. Barat and P. Amoros, Angew. Chem., Int. Ed., 2009, 48, 5884-5887.

123 S.-W. Song, K. Hidajat and S. Kawi, Chem. Commun., 2007, 43964398.

124 Q. Gao, Y. Xu, D. Wu, y. Sun and X. Li, J. Phys. Chem. C, 2009, 113, 12753-12758.

125 Y. Zhu, J. Shi, W. Shen, X. Dong, J. Feng, M. Ruan and Y. Li, Angew. Chem., Int. Ed., 2005, 44, 5083-5087.

126 L. Du, S. Liao, H. A. Khatib, J. F. Stoddart and J. I. Zink, J. Am. Chem. Soc., 2009, 131, 15136-15142.

127 J. M. Xue and M. Shi, J. Controlled Release, 2004, 98, 209-217.

128 B. G. Trewyn, C. M. Whitman and V. S.-Y. Lin, Nano Lett., 2004, 4, $2139-2143$.

129 A. L. Doadrio, E. M. B. Sousa, J. C. Doadrio, J. Perez-Pariente, I. Izquierdo-Barba and M. Vallet-Regi, J. Controlled Release, 2004, 97, 125-132.

130 J. C. D. M. Vallet-Regi, A. L. Doadrio, I. Izquierdo-Barba and J. Perez-Pariente, Solid State Ionics, 2004, 172, 435-439.

131 W. Zeng, X.-F. Qian, J. Yin and Z.-K. Zhu, Mater. Chem. Phys., 2006, 97, 437-441.

132 Y. Liu, H. Miyoshi and M. Nakamura, Colloids Surf., B, 2007, 58, 180-187.

133 A. Sousa, K. C. Souza and E. M. B. Sousa, ActaBiomaterialia, 2008, 4, 671-679.

134 I. I. Slowing, B. G. Trewin and V. S.-Y. Lin, J. Am. Chem. Soc., 2007, 129, 8845-8849.

135 I. Y. Park, I. Y. Kim, M. K. Yoo, Y. J. Choi, M.-H. Cho and C. S. Cho, Int. J. Pharm., 2008, 359, 280-287. 
136 C.-H. Lee, L.-W. Lo, C.-Y. Mou and C.-s. Yang, Advanced Functional Materials, 20088, 18, pp. 3283-3292.

137 L. Chen, G. Zhu, D. Zhang, H. Zhao, M. Guo, W. Shi and S. Qiu, J. Mater. Chem., 2009, 19, 2013-2017.

138 J. Liu, A. Stace-Naughton, X. Jiang and C. J. Brinker, J. Am. Chem. Soc., 2009, 131, 1354-1355.

139 A. Schlossbauer, J. Kecht and T. Bein, Angew. Chem., Int. Ed., 2009, 48, 3092-3095.

140 H. Lin, G. Zhu, J. Xing, B. Gao and S. Qiu, Langmuir, 2009, 25 , 10159-10164.

141 S. Huang, Y. Fan, Z. Cheng, D. Kong, P. Yang, Z. Wuan, C. Zhang and J. Lin, J. Phys. Chem. C, 2009, 113, 1775-1784.

$142 \mathrm{H}$. Yu and Q.-Z. Zhai, Microporous Mesoporous Mater., 2009, 123, 298-305.

143 D. P. Ferris, Y.-L. Zaho, N. M. Khashab, H. A. Khatib, J. F. Stoddart and J. I. Zink, J. Am. Chem. Soc., 2009, 131, 1686-1688

144 C. Park, H. Kim, S. Kim and C. Kim, Journal of American Chemical Society, 2009, 131

145 C. Chen, J. Geng, F. Pu, X. Yang, J. Ren and X. Qu, Angewandte Chemie International Edition, 2010, Articles ASAP.

146 D. R. Radu, C.-Y. Lai, J. W. Wiench, M. Pruski and V. S.-Y. Lin, J. Am. Chem. Soc., 2004, 126, 1640-1641.

147 S. Giri, B. G. Trewyn, M. P. Stellmaker and V. S.-Y. Lin, Angew. Chem., Int. Ed., 2009, 44, 5038-5044.

148 J.-H. Park, Y.-H. Lee and S.-G. Oh, Macromol. Chem. Phys., 2007, 208, 2419-2427.

149 P.-W. Chung, R. Kumar, M. Pruski and V. S.-Y. Lin, Adv. Funct. Mater., 2008, 18, 1390-1398.

150 K. Zhang, W. Wu, K. Guo, J. Chen and P. Zhang, Langmuir, 2010, 26, 7971-7980.

151 C. R. Thomas, D. P. Ferris, J.-H. Lee, E. Choi, M. H. Cho, E. S. Kim, J. F. Stoddart, J.-S. Shin, J. Cheon and J. I. Zink, J. Am. Chem. Soc., 2010, 132, 10623-10625.

152 H. Zou, S. Wu and J. Shen, Chem. Rev., 2008, 108, 3893-3957.

153 M. barari and n. Sharifi-Sanjanai, J. Appl. Polym. Sci., 2008, 110, 929-937.

154 J. Ho, Y. Huang, M. K. Danquah, H. Wang and G. M. Forde, Eur. J. Pharm. Sci., 2010, 39, 412-420.

155 D. Moelans, P. Cool, J. Baeyens and E. F. Vansant, Catal. Commun., $2005,6,307-311$

156 M. Griffiths, Oecd, Paris, 2001.

157 M. J. E. C. van der Maarel, B. van der Veen, J. C. M. Uitdehaag, H. Leemhuis and L. Dijkhuizen, J. Biotechnol., 2002, 94, 137-155.

158 J. Rajendhran and P. Gunasekaran, Journal of Bioscience and Bioengineering, 2004, 97, 1-13.

159 J. Kim, J. W. Grate and P. Wang, Chem. Eng. Sci., 2005, 61, 1017 1026.

160 W. D. Marner, II, A. S. Shaikh, S. J. Muller and J. D. Keasling, Biotechnol. Prog., 2009, 25, 417-423.

161 C. Ispas, I. Sokolov and S. Andreescu, Anal. Bioanal. Chem., 2009, 393, 543-554.

162 W. Marconi, React. Polym., 1989, 11, 1-19.

163 D. Brady and J. Jordaan, Biotechnol. Lett., 2009, 31, 1639-1650.

164 Y. Deng, C. Deng, D. Qi, C. Liu, J. Liu, X. Zhang and D. Zhao, Adv. Mater., 2009, 21, 1377-1382.

165 J. F. Diaz and K. J. Balkus, Jr, J. Mol. Catal. B: Enzym., 1996, 2 $115-126$.

166 H. H. P. Yiu and P. A. Wright, J. Mater. Chem., 2005, 15, 36903700.

167 D. Zhao, J. Feng, Q. Huo, N. Melosh, G. H. Frederickson, B. F. Chmelka and G. D. Stucky, Science, 1998, 279, 548-552.

168 H. H. P. Yiu, C. H. Botting, N. P. Botting and P. A. Wright, Phys. Chem. Chem. Phys., 2001, 3, 2983-2985.

169 J. Sun, H. Zhang, R. Tian, D. Ma, X. Bao, D. S. Su and H. Zou, Chem. Commun., 2006, 1322-1324.

170 J. Liu, C. Li, Q. Yang, J. Yang and C. Li, Langmuir, 2007, 23, 7255 7262.

171 J. Fan, C. Yu, F. Gao, J. Lei, B. Tian, L. Wang, Q. Luo, B. Tu, W. Zhou and D. Zhao, Angew. Chem., Int. Ed., 2003, 42, 3146-3150.

172 A. S. M. Chong and X. S. Zhao, Catal. Today, 2004, 93-95, 293-299.
173 G. Alvaro, R. Fernandez-Lafuente, R. M. Blanco and J. M. Guisan, Appl. Biochem. Biotechnol., 1990, 26, 181-195.

174 Y. Lue, Y. Guo, Y. Wang, X. Liu, Y. Wang, Y. Guo, Z. Zhang and G. Lu, Microporous Mesoporous Mater., 2008, 114, 507-510.

175 C. Lei, Y. Shin, J. Liu and E. J. Ackerman, J. Am. Chem. Soc., 2002, 124, 11242-11243.

176 A. K. Johnson, A. M. Zawadzka, L. A. Deobald, R. L. Crawford and A. J. Paszczynski, J. Nanopart. Res., 2008, 10, 10091025.

177 B. Shi, Y. Wang, Y. Guo, Y. Wang, Y. Wang, Y. Guo, Z. Zhang, X. Liu and G. Lu, Catal. Today, 2009, 148, 184-188.

178 X.-Y. Yang, Z.-Q. Li, B. Liu, A. Klein-Hofmann, G. Tian, Y.F. Feng, Y. Ding, D. Su and F.-S. Xiao, Adv. Mater., 2006, 18, $410-414$.

179 S.-F. Torabi, K. Khajeh, S. Ghasempur, N. Ghaemi and R. Siadat Seyed-Omid, J. Biotechnol., 2007, 131, 111-120.

180 S.-i. Matsuura, R. Ishii, T. Itoh, S. Hamakawa, T. Tsunoda, T. Hanaoka and F. Mizukami, Mater. Lett., 2009, 63, 2445-2448.

181 P. Shah, N. Sridevi, A. Prabhune and V. Ramaswamy, Microporous Mesoporous Mater., 2008, 116, 157-165.

182 S. B. Hartono, S. Z. Qiao, J. Liu, K. Jack, B. P. Ladewig, Z. Hao and G. Q. M. Lu, J. Phys. Chem. C, 2010, 114, 8353-8362.

183 D. A. Gaffney, S. O'Neill, M. C. O'Loughlin, U. Hanefeld, J. C. Cooney and E. Magner, Chem. Commun., 2010, 46, 1124-1126.

184 R. Herdt Aimee, B.-S. Kim and T. A. Taton, Bioconjugate Chem., 2007, 18, 183-189.

185 M. Miyazaki and H. Maeda, Trends Biotechnol., 2006, 24, 463-470.

186 C. Xu, K. Xu, H. Gu, X. Zhong, Z. Guo, R. Zheng, X. Zhang and B. Xu, J. Am. Chem. Soc., 2004, 126, 3392-3393.

187 T. Lummerstorfer and H. Hoffmann, J. Phys. Chem. B, 2004, 108, 3963-3966.

188 N. D. Gallant, K. A. Lavery, E. J. Amis and M. L. Becker, Adv. Mater., 2007, 19, 965-969.

189 J. He, X. Li, D. G. Evans, X. Duan and C. Li, J. Mol. Catal. B: Enzym., 2000, 11, 45-53.

190 H. Takahashi, B. Li, T. Sasaki, C. Miyazaki, T. Kajino and S. Inagaki, Chem. Mater., 2000, 12, 3301-3305.

191 H. H. P. Yiu, P. A. Wright and N. P. Botting, Microporous Mesoporous Mater., 2001, 44-45, 763-768.

192 W. Fadnavis Nitin, V. Bhaskar, L. Kantam Mannepalli and M. Choudary Boyapati, Biotechnol. Prog., 2003, 19, 346-351.

193 J. M. Gomez, J. Deere, D. Goradia, J. Cooney, E. Magner and B. K. Hodnett, Catal. Lett., 2003, 88, 183-186.

194 Z. Dai, S. Liu, H. Ju and H. Chen, Biosens. Bioelectron., 2004, 19, 861-867.

195 Z. Dai, X. Xu and H. Ju, Anal. Biochem., 2004, 332, 23-31.

196 E. Serra, A. Mayoral, Y. Sakamoto, R. M. Blanco and I. Diaz, Microporous Mesoporous Mater., 2008, 114, 201-213.

197 H. G. Manyar, E. Gianotti, Y. Sakamoto, O. Terasaki, S. Coluccia and S. Tumbiolo, J. Phys. Chem. C, 2008, 112, 18110-18116.

198 H. Sorensen Malin, B. S. Ng Jovice, L. Bergstrom and C. A. Alberius Peter, J. Colloid Interface Sci., 2010, 343, 359-365.

199 T. Itoh, R. Ishii, S.-i. Matsuura, J. Mizuguchi, S. Hamakawa, T.-A. Hanaoka, T. Tsunoda and F. Mizukami, Colloids Surf., B, 2010, 75, 478-482.

200 Y. Li, G. Zhou, W. Qiao and Y. Wang, Materials Science \& Engineering, B: Advanced Functional Solid-State Materials, 2009, 162, 120-126.

201 X. Huang, X. Teng, D. Chen, F. Tang and J. He, Biomaterials, 2010, 31, 438-448.

202 T. Y. Nara, H. Togashi, C. Sekikawa, K. Inoh, K. Hisamatsu, K. Sakaguchi, F. Mizukami and T. Tsunoda, J. Mol. Catal. B: Enzym., 2010, 64, 107-112.

203 Q. He, Z. Zhang, F. Gao, Y. Li and J. Shi, Small, 2011, 7, 271-280.

204 Q. He, J. Shi, M. Zhu, Y. chen and F. chen, Microporous Mesoporous Mater., 2010, 131, 314-320.

205 R. Mortera, S. Fiorilli, E. Verne and B. Onida, Chem. Eng. J., 2010, 156, 184-192.

206 W. Xu, Q. Gao, y. Xu, D. Wu and Y. Sun, Mater. Res. Bull., 2009, 44, 606-612. 